\title{
DOSIS \& DOSIS 3D: radiation measurements with the DOSTEL instruments onboard the Columbus Laboratory of the ISS in the years 2009-2016
}

Thomas Berger $^{1, *}$, Sönke Burmeister ${ }^{2}$, Daniel Matthiä ${ }^{1}$, Bartos Przybyla ${ }^{1}$, Günther Reitz ${ }^{1}$, Pawel Bilski ${ }^{3}$, Michael Hajek ${ }^{4,5}$, Lembit Sihver ${ }^{5,6}$, Julianna Szabo ${ }^{7}$, Iva Ambrozova ${ }^{8}$, Filip Vanhavere ${ }^{9}$, Ramona Gaza ${ }^{10,11}$, Edward Semones $^{10}$, Eduardo G. Yukihara ${ }^{12}$, Eric R. Benton ${ }^{12}$, Yukio Uchihori ${ }^{13}$, Satoshi Kodaira ${ }^{13}$, Hisashi Kitamura ${ }^{13}$, and Matthias Boehme ${ }^{14}$

1 German Aerospace Center (DLR), Institute of Aerospace Medicine, Linder Höhe, 51147 Köln, Germany

*Corresponding author: thomas.berger@dlr.de

2 Christian Albrechts Universität zu Kiel (CAU), Christian-Albrechts-Platz, 24118 Kiel, Germany

3 Institute of Nuclear Physics Polish Academy of Sciences (IFJ), PL-31342 Krakow, Poland

4 International Atomic Energy Agency (IAEA), Division of Radiation, Transport and Waste Safety, 1400 Vienna, Austria

5 Technische Universität Wien, Atominstitut (ATI), Stadionallee 2, 1020 Vienna, Austria

6 EGB MedAustron, Marie-Curie-Straße 5, 2700 Wiener Neustadt, Austria

7 Centre for Energy Research, (MTA EK), Konkoly Thege ut 29-33, 1121 Budapest, Hungary

8 Nuclear Physics Institute of the CAS (NPI), Department of Radiation Dosimetry, Na Truhlarce 39/64, 18000 Prague, Czech Republic

9 Belgian Nuclear Research Center (SCK•CEN), Boeretang 200, 2400 Mol, Belgium

10 NASA, Space Radiation Analysis Group (NASA/SRAG), Houston, TX 77058, USA

11 Leidos, Exploration \& Mission Support, 2400 NASA Pkwy, Houston, TX 77058, USA

12 Physics Department, Oklahoma State University (OSU), Stillwater, OK 74078, USA

13 National Institute of Radiological Sciences (NIRS), National Institutes for Quantum and Radiological Science and Technology (QST), 4-9-1 Anagawa, Inage, Chiba 263-8555, Japan

14 OHB System AG, Universitätsallee 27-29, 28359 Bremen, Germany

Received 2 November 2016 / Accepted 30 January 2017

\section{ABSTRACT}

The natural radiation environment in Low Earth Orbit (LEO) differs significantly in composition and energy from that found on Earth. The space radiation field consists of high energetic protons and heavier ions from Galactic Cosmic Radiation (GCR), as well as of protons and electrons trapped in the Earth's radiation belts (Van Allen belts). Protons and some heavier particles ejected in occasional Solar Particle Events (SPEs) might in addition contribute to the radiation exposure in LEO. All sources of radiation are modulated by the solar cycle. During solar maximum conditions SPEs occur more frequently with higher particle intensities. Since the radiation exposure in LEO exceeds exposure limits for radiation workers on Earth, the radiation exposure in space has been recognized as a main health concern for humans in space missions from the beginning of the space age on. Monitoring of the radiation environment is therefore an inevitable task in human spaceflight. Since mission profiles are always different and each spacecraft provides different shielding distributions, modifying the radiation environment measurements needs to be done for each mission. The experiments "Dose Distribution within the ISS (DOSIS)" (2009-2011) and "Dose Distribution within the ISS 3D (DOSIS 3D)" (2012-onwards) onboard the Columbus Laboratory of the International Space Station (ISS) use a detector suite consisting of two silicon detector telescopes (DOSimetry TELescope $=$ DOSTEL) and passive radiation detector packages (PDP) and are designed for the determination of the temporal and spatial variation of the radiation environment. With the DOSTEL instruments' changes of the radiation composition and the related exposure levels in dependence of the solar cycle, the altitude of the ISS and the influence of attitude changes of the ISS during Space Shuttle dockings inside the Columbus Laboratory have been monitored. The absorbed doses measured at the end of May 2016 reached up to $286 \mu$ Gy/day with dose equivalent values of $647 \mu \mathrm{Sv} /$ day.

Key words. International Space Station - Columbus - Space radiation - DOSTEL - DOSIS 3D

\section{Introduction}

The natural radiation environment in Low Earth Orbit (LEO) differs significantly in composition and energy from that found on Earth. It consists of protons and heavier ions from Galactic Cosmic Radiation (GCR) of energies up to $10^{20} \mathrm{eV}$, as well as protons and electrons trapped in the Earth's radiation belts having energies up to $600 \mathrm{MeV}$ and $7 \mathrm{MeV}$, respectively. Protons and heavier particles with energies up to several gigaelectron-volts $(\mathrm{GeV})$ emitted in occasional Solar Particle Events (SPEs) increase the complexity of the radiation field. The radiation field in LEO is dependent on altitude and inclination of the spacecraft orbit and changes with the solar activity. Particles of all sources are capable of entering the 
spacecraft. The interactions of the particles with the atoms of the spacecraft material and the human body lead to a release of orbital electrons due to ionization as well as to production of new particles such as mesons, pions, secondary protons, neutrons and heavy ions through fragmentation of the primary particles or target fragmentation through nuclear collisions. As a result, the exposure the crew receives during an extended spaceflight significantly exceeds exposure limits for terrestrial radiation workers (Reitz 2008).

Since the early times of human spaceflight, space radiation and especially its heavy ion component has been recognized as a main health concern for human space missions (Grahn 1973; Durante \& Cucinotta 2011). The monitoring of the radiation exposure received by humans already started in the 1960s with the Mercury and Gemini missions (Warren \& Gill 1964; Richmond 1972) and the Apollo missions to the Moon (see for example English et al. 1973 and also http://history.nasa. gov/SP-368/contents.htm). The experiment suite applied at these times already consisted of passive (integrating) and time-resolving active (battery or otherwise powered) detectors.

For the ISS more advanced instruments were developed and methods are refined, since due to the extended stay of humans more detailed knowledge on the radiation field is needed to be provided also to ensure radiation protection measures. Onboard the ISS active and passive dosimetry was and is therefore accomplished with various detector systems (see reviews in Berger 2008; Caffrey \& Hamby 2011; ICRP 2013 and Narici et al. 2015). In the frame of the DOSIS and DOSIS 3D experiments, active instruments based on silicon detector technology and passive radiation detectors were and are applied for long time dose monitoring onboard the Columbus Laboratory of the ISS. For the first results of the passive radiation detectors onboard the Columbus Laboratory, the reader is referred to Berger et al. (2016).

\section{The DOSIS and DOSIS 3D experiments: active detectors}

The aim of the DOSIS (2009-2011) and the subsequent DOSIS 3D (2012-ongoing) experiments was and is the measurement of the radiation environment within the European Columbus Laboratory of the ISS. These measurements are carried out with two silicon detector telescopes (DOSimetry TELescope $=$ DOSTEL) mounted at a fixed position inside Columbus for the determination of the temporal variation of the radiation field parameters. In addition, 11 Passive Detector Packages (PDP) are applied for the measurement of the spatial distribution of the radiation exposure within Columbus and long-term temporal evolution of the radiation field parameters (see Berger et al. 2016).

The DOSTEL instrument, jointly developed by CAU, Kiel, Germany \& DLR, Cologne, Germany, and applied within DOSIS and the DOSIS 3D experiments has its heritage from numerous space missions. Its first version was applied for measurements in the Biorack facility of the European Space Agency (ESA) onboard various Space Shuttle missions namely: STS-76 (March 1996), STS-81 (January 1997) and STS-84 (May 1997) (Reitz et al. 1998; Beaujean et al. 1999a, 1999b; Reitz et al. 1999; Singleterry et al. 2001). The instruments were further mounted in the Kristall module of the MIR space station from October 1997 to January 1998 as part of the Active Dosimetry of Charged Particle (ADCP) experiment, which was flown as part of the NASA-6 mission to the MIR space station. During this time it measured the first Ground Level Enhancement (GLE) of the 23rd Solar Cycle on November 06th 1997 (GLE-55) (Badhwar et al. 2002; Beaujean et al. 2002; see also http://cosmicrays.oulu.fi/GLE.html).

Two additional DOSTEL instruments were used as part of the first European Dosimetry experiment, the Dosimetric Mapping (DosMap) experiment, onboard the US Laboratory (US Lab) of the ISS between March and August 2001 (Reitz et al. 2005). Also during the DosMap mission it was possible to get data from another GLE, namely GLE-60 in the middle of April 2001 (see also http://cosmicrays.oulu.fi/GLE.html). A further upgraded version of the DOSTEL was flown as part of the active dosimetry suite of the MATROSHKA experiment outside and inside the ISS in the years 2004-2011 (Labrenz et al. 2015). The instruments were also used for measurements onboard airplanes (Beaujean et al. 1999c, 2005) and worth to mention is that the principal design of the DOSTEL is also reflected in the MSL-RAD instrument that measured the radiation environment during the cruise to Mars and it is currently performing measurements on its surface (Zeitlin et al. 2013; Hassler et al. 2014).

\subsection{DOSIS and DOSIS 3D experiments: active hardware}

The active part of the DOSIS \& DOSIS 3D hardware consists of two DOSTELs (DOSTEL-1 and DOSTEL-2) and the DOSTEL Data and Power Unit (DDPU). The two instruments and the DDPU are mounted in a Nomex ${ }^{\odot}$ Box, called the DOSISMAIN-BOX, at a fixed position beneath the European Physiology Module (EPM) in Columbus. Inside the DOSISMAIN-BOX the DOSTELs are mounted in such a way, that the telescope of DOSTEL-1 is directed parallel (X), whereas the telescope of DOSTEL-2 is directed perpendicular (Y) to the ISS flight direction (see Fig. 1a). This arrangement allows receiving information about the directionality of the radiation field inside Columbus. For a comparison of the data with those of the passive radiation detectors, one PDP is always attached to the left side of the DOSIS-MAIN-BOX (see Fig. 1b).

Each DOSTEL houses two passivated implanted planar silicon (PIPS) detectors (D-1 and D-2) each with a thickness of $315 \mu \mathrm{m}$ and an active area of $6.93 \mathrm{~cm}^{2}$ arranged in a telescope geometry mounted at a distance of $15 \mathrm{~mm}$ thereby yielding a telescope with an opening angle of $120^{\circ}$ and a geometric factor of $824 \mathrm{~mm}^{2}$ sr. With this detector configuration, the DOSTEL measures count rates and dose rates of radiation hitting a single detector ("dose measurement") and coincidental hits in the two detectors with a limited path length in the detectors to derive information about the linear energy transfer (LET) ("telescope" or "LET" measurement). Based on the measured data DOSTEL provides absorbed dose and dose equivalent values.

Each detector (D-1 and D-2) in the individual DOSTEL units is connected to an independent analogue signal section consisting of a charge-sensitive preamplifier with $2 \mathrm{pF}$ integrating capacitor followed by a two-stage pulse amplifier and two peak detectors. The two-stage pulse amplifier for the D-1 detector has a gain factor of 4 for the first stage and 30 for the second stage, which results in a total gain of 120 for D-1. For D-2 the two-stage pulse amplifier has a gain factor of 10 for the first stage and 20 for the second stage, which results in a total gain factor of 200 for D-2. Together with an 8-bit ADC this design allows a pulse height analysis of 

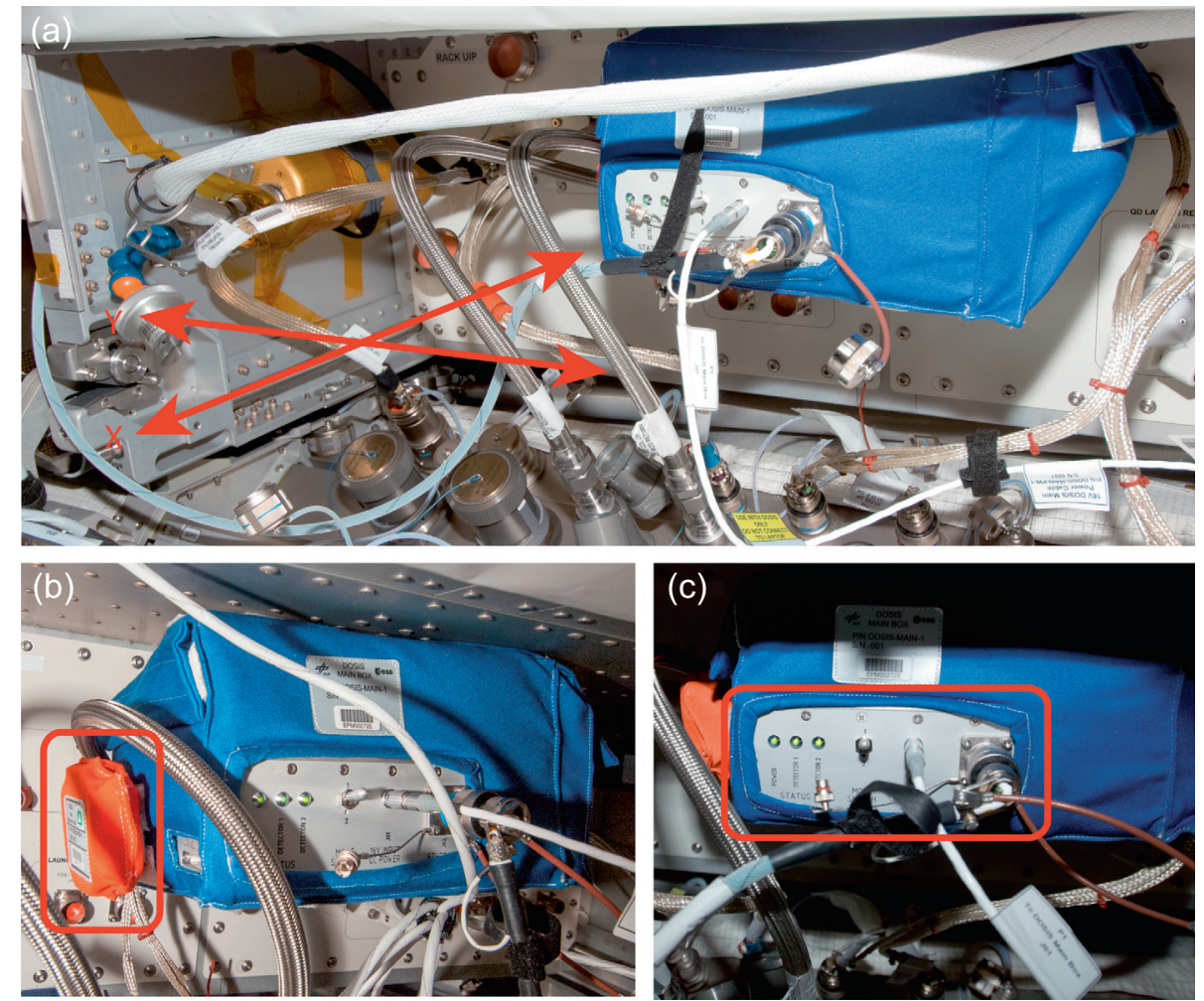

Fig. 1. (a) The DOSIS-MAIN-BOX (blue box) mounted beneath the EPM rack in Columbus. Shown is also the viewing direction of the DOSTEL-1 (X) and the DOSTEL-2 (Y) instruments; (b) the Passive Detector Package (PDP) mounted directly at the DOSIS-MAIN-BOX; (c) the DOSIS-MAIN-BOX front panel with LED status bar, MODE Switch for DOSTEL-1 (see Sect. 3.1), Power and Data connector. Source: NASA/ESA.

Table 1. Exposure times for the active detectors within the DOSIS and DOSIS 3D experiments.

\begin{tabular}{|c|c|c|c|c|c|c|}
\hline & Detector & Timeline & & Measurement period & Data [days] & ISS alt. [km] \\
\hline \multirow[t]{8}{*}{ DOSIS } & DOSTEL- $1^{(1)}$ & Launch (STS-127) & July 15, 2009 & July $18,2009-$ May 28,2010 & 290 & $337-350$ \\
\hline & & Installation & July 18,2009 & & & \\
\hline & & Retrieval & April 21, 2011 & & & \\
\hline & & Return (Soyuz 25S) & May 24, 2011 & & & \\
\hline & DOSTEL-2 & Launch (STS-127) & July 15, 2009 & July 18, 2009-June 16, 2011 & 645 & $337-375$ \\
\hline & & Installation & July 18,2009 & & & \\
\hline & & Retrieval & June 17,2011 & & & \\
\hline & & Return (STS-135) & July 21, 2011 & & & \\
\hline \multirow[t]{2}{*}{ DOSIS 3D } & DOSTEL-1/-2 & Launch (Soyuz 30S) & May 15, 2012 & May 21, 2012-May 31, 2016 & 1396 & $398-418$ \\
\hline & & Installation & May 21, 2012 & & 1391 & \\
\hline
\end{tabular}

(1) DOSTEL-1 stopped acquiring data after 290 measurement days in space at May 28th 2010.

the detector signals with different resolution for the low and high energy deposition region.

This leads to an energy deposition range (in silicon) of $0.069-165 \mathrm{MeV}$ for the top D-1 detector and of 0.048-66 MeV for the bottom D-2 detector. With the limit in path length for the coincidence mode the linear energy transfer (LET) range in water covered by the instruments is $0.1-240 \mathrm{keV} / \mu \mathrm{m}$ for $\mathrm{D}-1$ and $0.07-95 \mathrm{keV} / \mu \mathrm{m}$ for $\mathrm{D}-2$; therefore, the resolution of the latter, especially in the region of low energy depositions, is higher (see also in detail Sect. 3.2).

The digital signal section of the instruments consists of an 8-bit MCU (68HC711), a timer, a 1 MB flash memory and $32 \mathrm{kB}$ RAM. Science data as well as housekeeping data for a 12-day period can be stored in the flash memory of the
DOSTEL. After this period data is downloaded via the RS-232 interface to the DDPU.

The DDPU provides the two DOSTEL instruments with power, stores the data from the instruments on an SD memory card and provides the interface to the Columbus modules. The DDPU is connected via a former NASA $16 \mathrm{~V}$ laptop power supply ("black brick") to a $120 \mathrm{~V}$ Columbus power outlet (SUP outlet) for the provision of the power to the instruments. Furthermore, the DDPU has a data connection (see Fig. 1c) via the EPM LAN interface at the upper right part of the EPM facility. The scientific and housekeeping data are downloaded by the EPM rack via Ethernet connection nominally every four weeks. For this the EPM rack is activated once a month. The total power consumption of the DOSIS experiment is about $3 \mathrm{~W} @ 16 \mathrm{~V}$. 
Table 2. DOSTEL measurement modes and relevant stored science data.

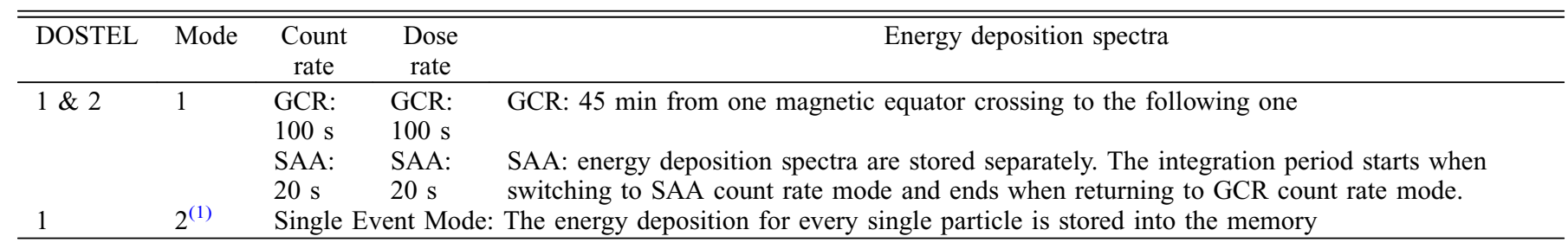

(1) The data produced by every single particle in both detectors of the DOSTEL-1 telescope is stored (PHA data). Mode 2 is only started and stopped after switching the relevant MODE switch at the front side of the DOSIS-MAIN-BOX (nominally once or twice a year for around 7 days) (see also Fig. 1c).

\subsection{DOSIS and DOSIS 3D experiments: active timeline}

The DOSIS experiment was launched with Space Shuttle STS-127 (Endeavour) to the ISS on July 15th 2009. The DOSIS-MAIN-BOX was installed beneath the EPM rack on July 18th 2009 and at the same day powered on. Within the DOSIS experiment phase the DOSTEL-1 instrument measured for 290 days till May 28th 2010 (see Table 1). It stopped acquiring data due to a hardware failure and was retrieved and brought back to ground with Soyuz 25S on May 24th 2011. The DOSTEL-2 instrument worked till the end of the DOSIS experiment and provided data for 645 days till June 16th 2011. It was delivered back to Earth together with the DDPU with the last Space Shuttle mission to the ISS STS-135 (Atlantis) on July 21st 2011.

The two DOSTEL instruments and the DDPU were refurbished for their next mission to the station in the frame of the DOSIS 3D experiment in the year 2012. On May 15th 2012 the DOSIS 3D experiment was launched with Soyuz 30 S and the DOSIS-MAIN-BOX was installed at the same location beneath EPM as for the DOSIS mission on May 21st 2012. From this day onwards both DOSTEL units measured and are still measuring. For the current publication DOSTEL data was taken up to May 31st 2016, covering thereby a four-year time period for the DOSIS 3D experiment.

\section{Materials and methods}

\subsection{DOSTEL: "On orbit" data products and dosimetry}

During their operation on orbit the two DOSTEL units measure independently the particle count- and absorbed dose rates and the energy deposition spectra. The particle rate as well as the dose rate is counted by each detector of each unit (D-1 and D-2) independently. While the particle rate is taken just by counting the hits during a given time interval the dose rate is evolved by summing up the Analogue to Digital Converter (ADC) values of the relevant hits. The $\mathrm{ADC}$ values represent the energy deposition in the detector; so the integral ADC values represent the total absorbed dose deposited in a single detector. After a given time interval the particle rate and the absorbed dose rate are stored in the DOSTEL memory. During nominal operation onboard the ISS, this integration period is set to $100 \mathrm{~s}$ (GCR) (see Table 2). The period was chosen to get sufficient counting statistics for the GCR count rates since the expected event rate varies between 3 and 30 counts/s while the station is located outside the region of the South Atlantic Anomaly (SAA). Inside the SAA the particle rate is significantly higher than in the rest of the orbit. Additionally, the energy spectrum of the particles in the SAA region differs from those measured in the other regions of the ISS orbit. Due to these reasons a count rate threshold is used to switch the DOSTELs from the so-called GCR Mode to the SAA Mode. In the SAA mode the integration period for the count rate and absorbed dose rate measurement is set to $20 \mathrm{~s}$ to obtain better time resolution (see also Table 2).

The measurement of the energy deposition spectra, with the subsequent calculation of the LET spectra, requires a coincidence in the two detectors (D-1 and D-2) of each DOSTEL, thereby also limiting the path length of the impinging particles. The integration period for the energy deposition spectra is initially set to $45 \mathrm{~min}$. To synchronize the data recording with the orbit of the ISS the minima in the count rates are used to start a new integration period for the spectra. These minima result from crossing the geomagnetic equator where the magnetic shielding of the Earth's magnetic field has its highest efficiency. Thus the energy deposition spectra are integrated over half orbits from one crossing of the geomagnetic equator to the next. Furthermore, the energy deposition spectra measured during SAA passes are stored separately to take into account the different particle species inside and outside this region. Since the mean quality factor is derived from the LET spectra it is possible to yield quality factors for the SAA region and the GCR component separately (see also in detail: Sect. 3 of Labrenz et al. 2015). During nominal operation count rate, dose rate and energy deposition spectra data is taken in parallel and these measurements are defined as socalled Mode 1 (Table 2).

In addition, it is possible to operate one of the DOSTEL units (DOSTEL-1) in the Mode 2 (so-called Single Event Mode). In Mode 2 every particle trigger in the D-1 or D-2 detectors of the DOSTEL-1 leads to the storage of the ADC values for both detectors. Though this Mode 2 is way more memory and bandwidth consuming it allows a deeper analysis of the data. In this mode particle species and directionality can be identified for certain energies. The switching between Mode 1 and Mode 2 for DOSTEL-1 is done by using the Mode Switch on the DDPU front panel (see also Fig. 1c).

To derive the relevant dosimetric quantities the following methods are used (see also in detail: Sect. 3 of Labrenz et al. 2015). To separate the dose induced by the GCR component only the northern hemisphere is used to ensure that no 
T. Berger et al.: DOSIS \& DOSIS 3D: DOSTEL radiation measurements on board the ISS

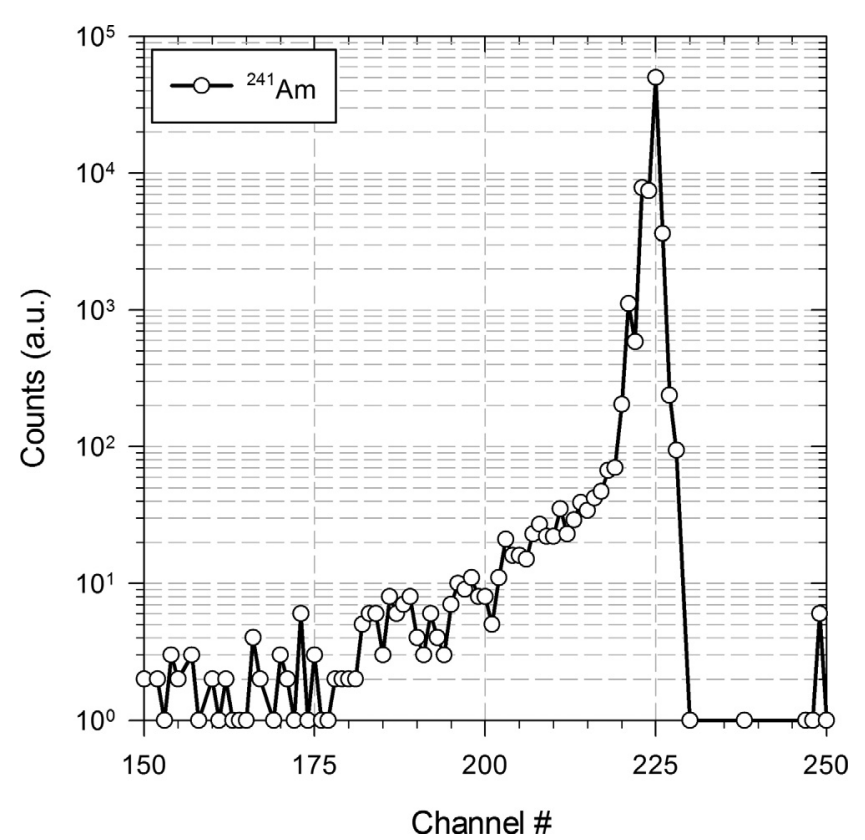

Fig. 2. Energy deposition spectrum for ${ }^{241} \mathrm{Am}$ applied in a vacuum chamber in front of the detector for initial calibration (high gain calibration).

contamination by SAA particles is tampering with the result. The dose measured on the northern hemisphere is multiplied by 2 to derive the total dose from GCR. This presupposes that the GCR dose distribution is symmetrical about the geomagnetic equator. To obtain the contribution of the trapped particle induced dose the GCR dose is subtracted from the total dose. Since the instruments can only measure the energy deposition in silicon one has to calculate the relevant quantities like absorbed dose in water and dose equivalent in water from this data. This is done by multiplying the dose in silicon by a constant factor of 1.23 . This factor originates from the different stopping powers for protons and electrons in silicon and water (ICRU 1984). This mean conversion factor does not take into account the dependence on particle type and energy and its uncertainty is estimated to be around 5\% (Labrenz et al. 2015).

To derive dose equivalent values, the data from the energy deposition spectra are used to calculate the respective LET spectra (in water) assuming a mean path length for penetrating particles measured in coincidence mode. For isotropic particle incidence the mean angle $a$ of incidence is $30^{\circ}$, and hence the mean path length $d l$ is $d l=d \cdot(\cos a)^{-1}$, where $d$ is the thickness of the detector. The mean path length used is therefore $364 \mu \mathrm{m}$ (for details see Chapter 6.2.2 of Labrenz 2014). The LET spectra in combination with the LET-dependent quality factors defined in ICRP60 (ICRP 1991) are used to calculate the mean quality factors (see also Labrenz et al. 2015) and with this the dose equivalent.

\subsection{DOSTEL: calibration}

The silicon detectors applied within the DOSTEL instrument have been thoroughly calibrated before launch with various radiation sources. For a more in-depth discussion of the calibration principles for the DOSTEL instruments, the reader

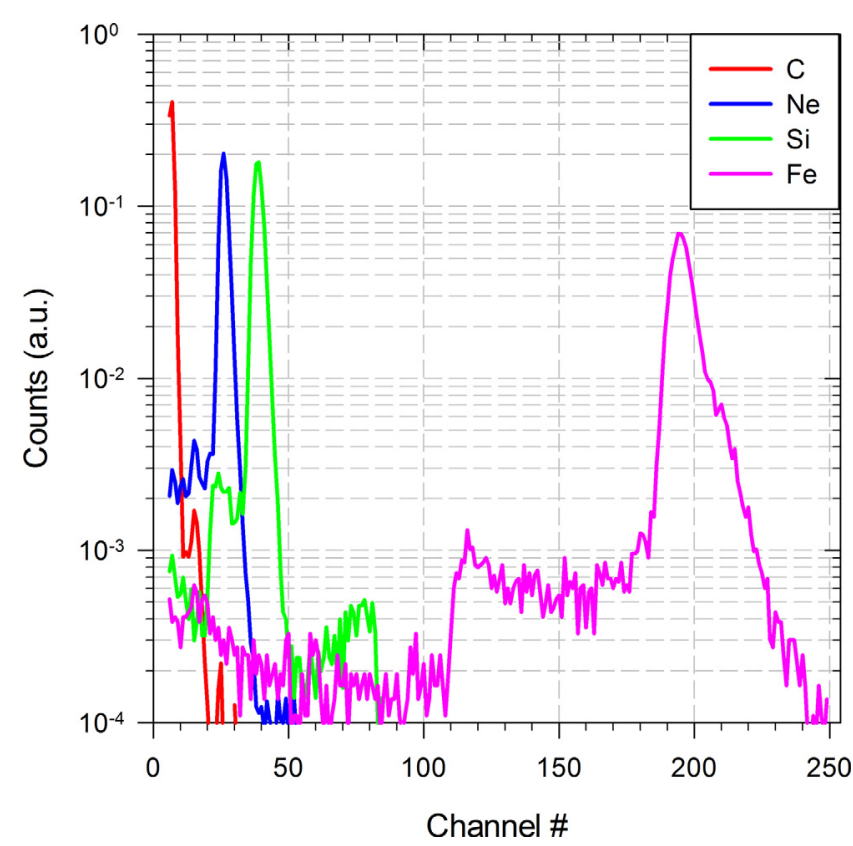

Fig. 3. Energy deposition spectra for $400 \mathrm{MeV} / \mathrm{u}$ carbon, $400 \mathrm{MeV} / \mathrm{u}$ neon, $800 \mathrm{MeV} / \mathrm{u}$ silicon and $500 \mathrm{MeV} / \mathrm{u}$ iron ions penetrating the detector perpendicularly (low gain calibration).

Table 3. DOSTEL energy deposition (in $\mathrm{Si}$ ) and LET (in $\mathrm{H}_{2} \mathrm{O}$ ) range for both telescope detectors (D-1 and D-2).

\begin{tabular}{lcc}
\hline \hline Detector & Energy $(\mathrm{Si})$ & LET $(\mathrm{keV} / \mu \mathrm{m})$ in $\mathrm{H}_{2} \mathrm{O}$ \\
\hline $\mathrm{D}-1$ & $69 \mathrm{keV}-165 \mathrm{MeV}$ & $0.1-240$ \\
$\mathrm{D}-2$ & $48 \mathrm{keV}-66 \mathrm{MeV}$ & $0.07-95$ \\
\hline
\end{tabular}

is referred to Beaujean et al. (1999a, 2002). For the initial calibration of the high gain amplifier chain of the electronics a first calibration step for the DOSTEL instruments was the exposure to ${ }^{241} \mathrm{Am}$ in a vacuum chamber (pressure $0.1 \mathrm{hPa}$, distance $10 \mathrm{~cm}$ ). ${ }^{241} \mathrm{Am}$ emits $\alpha$-particles of three different energies: $85 \%$ of the decays yields a $5.486 \mathrm{MeV} \alpha$-particle, $13 \%$ yields $5.443 \mathrm{MeV}$ and the remaining $2 \%$ are $5.388 \mathrm{MeV}$ $\alpha$-particles. Even though the lower $\alpha$ energies are also visible in Figure 2 only the main peak of $5.486 \mathrm{MeV}$ was used for calibration purposes.

The linearity of the electronics as well as the different gain factors of the high and low gain pulse amplifiers have been in addition checked by using an external test pulser.

To verify higher energy depositions in the low gain amplifier chain the instruments were irradiated over the years in the frame of the ICCHIBAN project with heavy ions at the Heavy Ion Medical Accelerator (HIMAC) of the National Institute of Radiological Sciences (NIRS) in Chiba, Japan (Uchihori \& Benton 2004, 2008). Parts of the results of these calibrations for the low gain amplifier are given in Figure 3. Figure 3 shows the relevant calibration peaks for carbon, neon, silicon and iron ions in the low gain amplifier chain, confirming that the DOSTEL instruments can detect particles up to iron, which is a prerequisite to perform accurate dosimetry in LEO. All these measurements led to the conclusion that calibration of the instruments is sufficient for dosimetric purposes. 


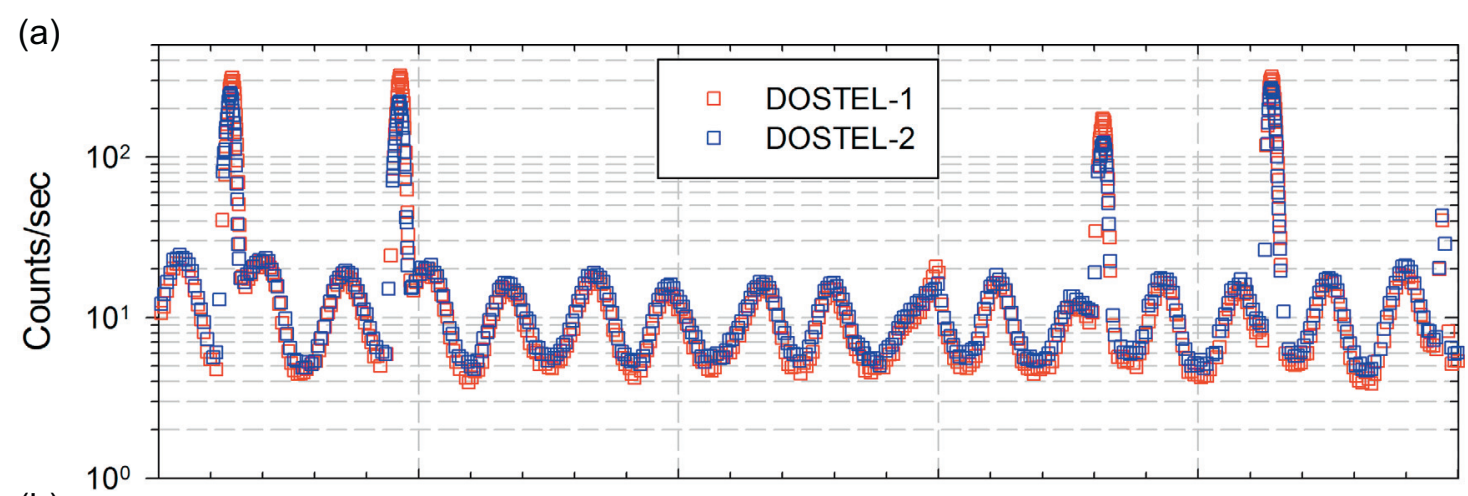

(b)

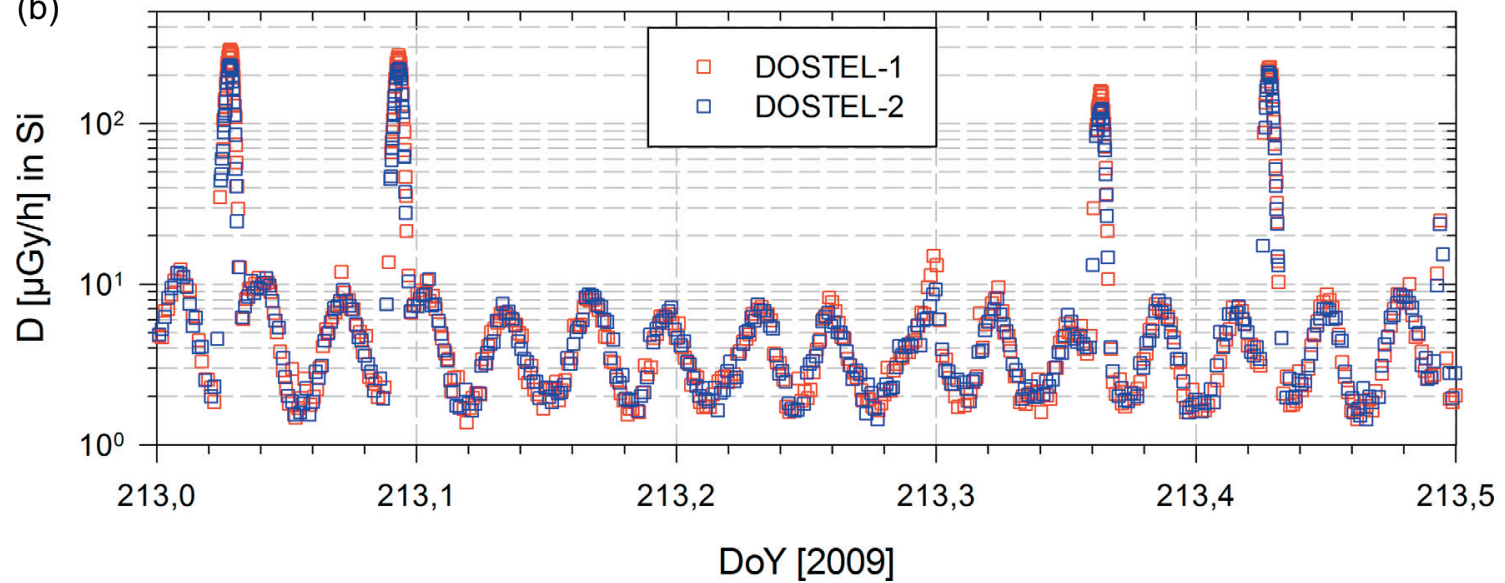

Fig. 4. Example of (a) count rates and (b) absorbed dose rates (in silicon) for a 12-h period in the year 2009 for the DOSTEL-1 (red) and the DOSTEL-2 (blue) instruments.

The resulting energy deposition ranges and therefore the resulting LET ranges are given in Table 3 for D-1 and D-2 for the DOSTEL instrument. For relevant dose measurements all energy deposition measurements exceeding the upper limit $\Delta E_{\mathrm{MAX}}$ for D-1 and D-2 are taken as $\Delta E_{\mathrm{MAX}}$. For the deduction of the mean quality factor all LET values exceeding the upper limit $\mathrm{LET}_{\mathrm{MAX}}$ for D-1 and D-2 are also taken as LET $_{\text {MAX }}$.

\section{Results and discussion}

Section 4 is structured in the following way. Section 4.1 presents the primary data measured with the DOSTEL instruments, namely the count and the absorbed dose rates. Further on, it focuses on relevant parameters influencing the measured absorbed dose onboard the ISS. These parameters are on one hand given by the natural radiation environment (solar cycle influence Sect. 4.1.1), on the other hand by changes in the ISS altitude (Sect. 4.1.2) and by changes in the ISS attitude due to the docking of the Space Shuttle (Sect. 4.1.3).

After the discussion of these relevant parameters influencing the absorbed dose measured inside the ISS we will focus on the long-term variation of the absorbed dose measured within the DOSIS and DOSIS 3D experiment phases (Sect. 4.2), the relevant LET spectra and their differences depending on solar cycle and ISS altitude (Sect. 4.3) and conclude with the dose equivalent values determined for DOSIS and DOSIS 3D (Sect. 4.4). Section 4.5 provides a comparison of data measured with other active and passive radiation detectors onboard the ISS throughout the DOSIS and DOSIS 3D experiment timeline.

\subsection{Count- and absorbed dose rates}

Figure 4 gives an example of the count rate (Fig. 4a) and absorbed dose rate (measured in Si) (Fig. 4b) versus elapsed time for a time period of $12 \mathrm{~h}$ measured with the DOSTEL-1 and the DOSTEL-2 instruments shortly after the successful installation in July 2009.

Figure 4 provides for both, the count and absorbed dose rates, the temporal variations due to changing magnetic cutoff conditions in dependence of latitude with minima at the magnetic equator after every $45 \mathrm{~min}$ and maxima at high latitude locations as well as the relevant spikes (in total six) during SAA crossings. While the first two SAA crossings between Day of Year (DoY) 213.0 and 213.1 are so-called descending nodes, i.e. the ISS comes from the equator and flies to higher southern geomagnetic latitudes, the other four crossings between 213.3 and 213.5 are related to so-called ascending nodes, i.e. the ISS comes from the south and flies in the direction of the equator to higher geomagnetic cutoffs. While for the absorbed dose due to GCR the dose values for both DOSTEL-1 and DOSTEL-2 are in quite good agreement we can see that the count rate and absorbed dose rates during the SAA crossing differ due to the highly anisotropic proton contributions in the SAA.

\subsubsection{Solar cycle influence on the absorbed dose rate of GCR}

It is well known that the sun and its 11-year solar cycle influence our radiation environment in space. The contribution from GCR varies with the activity of the sun and the connected interplanetary magnetic field. Therefore during solar minimum conditions the contributions from GCR are the highest, while 
(a)
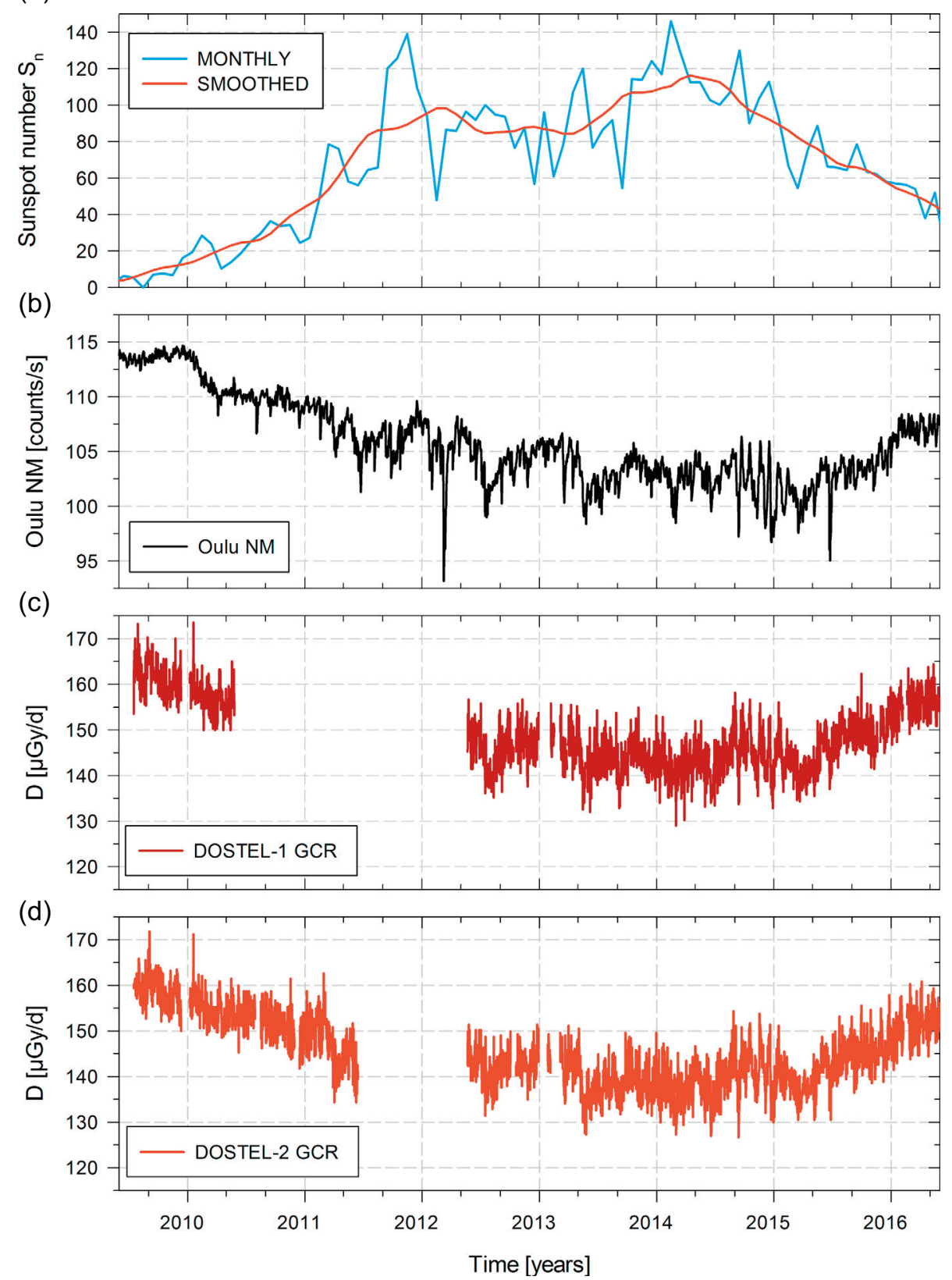

Fig. 5. (a) The monthly and smoothed sun spot number from June 2009 to June 2016; (b) Oulu NM count rates from June 2009 to June 2016; (c, d) the measured daily absorbed dose rate for the contribution of the GCR for the DOSTEL-1 and DOSTEL-2 instruments. Note: No measurements were taken from June 2010 to May 2011.

during solar maximum conditions the contributions from GCR are reduced due to the stronger interplanetary magnetic field preventing GCR of lower energies from entering the heliosphere. An indication of the activity of the sun is given by the sun spot number, and neutron monitors on ground provide measurements of the related GCR intensity with the highest values during solar minimum conditions and lowest values during solar maximum conditions. Figure 5 therefore provides the sunspot number (Fig. 5a; data from: http:// www.sidc.be/silso/) and the Oulu neutron monitor count rates (Fig. 5b; data from: http://cosmicrays.oulu.fi) for the timeframe $(06 / 2009-06 / 2016)$ of the DOSIS (07/2009-06/2011) and the DOSIS 3D (05/2012-onwards) experiments. Figure 5 also provides the measured daily absorbed dose rates for the
GCR contribution for the DOSTEL-1 instrument (Fig. 5c) and the DOSTEL-2 instrument (Fig. 5d).

The DOSIS mission started in July 2009, within the deepest solar minimum conditions (2009) in the spacefaring era. This is indicated by a sunspot number $S_{n} \sim 0$ and the highest Oulu Neutron Monitor count rates for the whole year 2009 and also reflected in the absorbed dose values measured by both DOSTEL instruments of up to $170 \mu \mathrm{Gy} /$ day. From 2010 onwards we observed a slow increase of solar activity which can nicely be seen in the DOSTEL data showing similar variations as the Oulu Neutron monitor count rate. The DOSTEL-2 instrument covered the slow increase in solar activity and the related decrease in GCR intensity till the end of the DOSIS experiment in June 2011. 
(a)

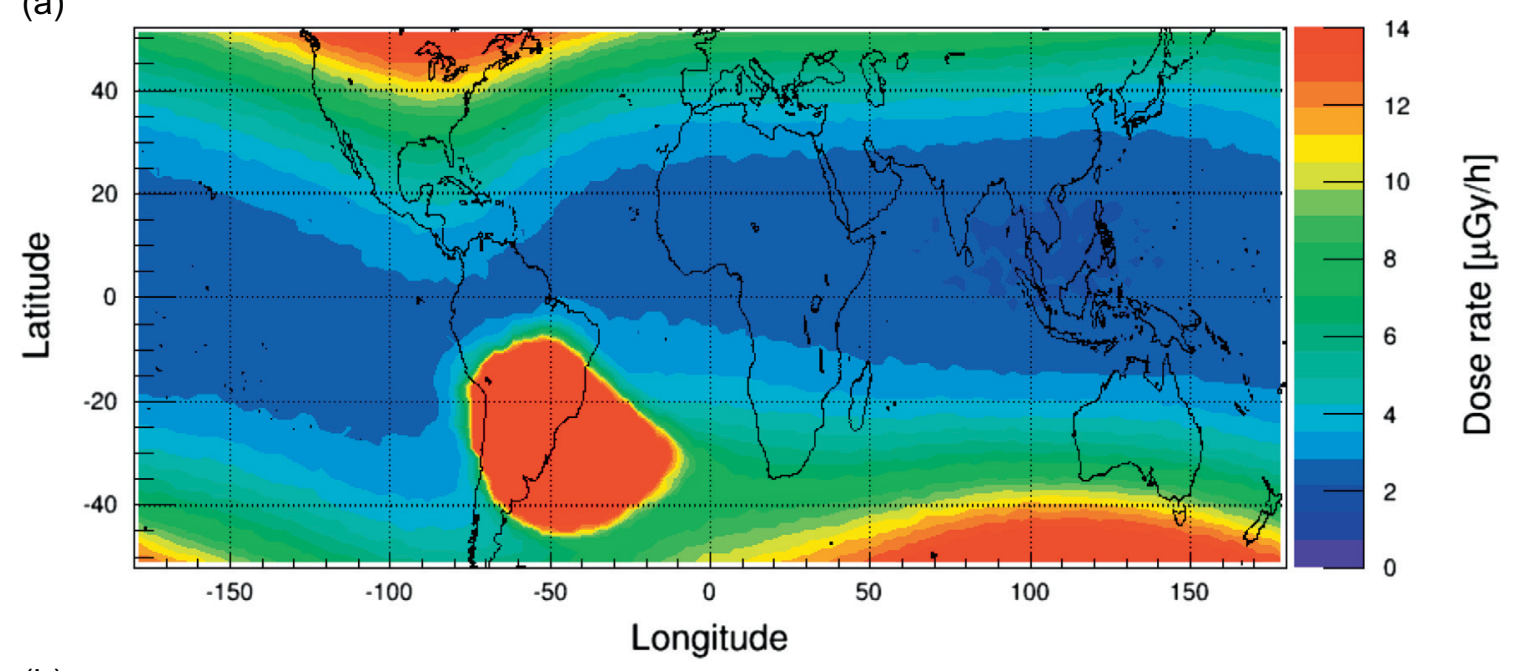

(b)

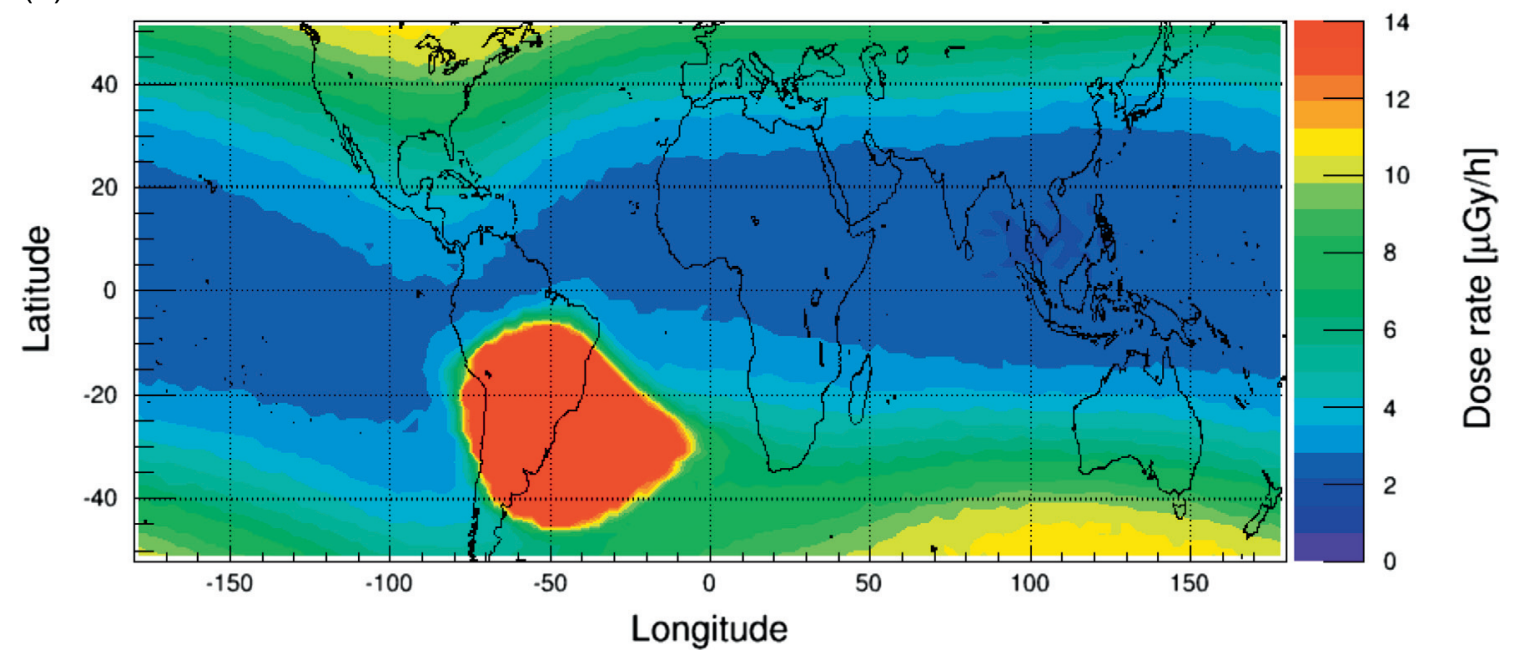

Fig. 6. The variation of the absorbed dose rate for solar minimum (a) DOSIS year 2009 and solar maximum (b) DOSIS 3D year 2013 conditions. The scale $(0 \mu \mathrm{Gy} / \mathrm{h}-14 \mu \mathrm{Gy} / \mathrm{h})$ was chosen to illustrate the variations in the dose rate from Galactic Cosmic Rays while the dose rate in most parts of the South Atlantic Anomaly (roughly between $10^{\circ} \mathrm{W}$ and $80^{\circ} \mathrm{W} ; 5^{\circ} \mathrm{S}$ and $45^{\circ} \mathrm{S}$ ) is above the scale.

With the start of DOSIS 3D in May 2012 we find ourselves in a weak solar maximum which lasted till the middle of 2014 resulting in an almost constant plateau of the absorbed dose rates of around $150 \mu \mathrm{Gy} /$ day for the DOSTEL-1 and $145 \mu \mathrm{Gy} /$ day for the DOSTEL-2 instrument. The decline towards a new solar minimum started at the beginning of the year 2015, which was accompanied by a steady increase in absorbed dose rates measured in both DOSTEL units until the end of the presented values (06/2016). The absorbed dose rates measured with DOSTEL-1 reached around $160 \mu \mathrm{Gy} /$ day at the end of May 2016.

For a better understanding of the changes in the GCR contribution Figure 6 presents the GCR variation coupled to the ISS orbital data for two distinct time periods. The scale $(0 \mu \mathrm{Gy} / \mathrm{h}-14 \mu \mathrm{Gy} / \mathrm{h})$ was chosen to visualize the variation of absorbed dose rate from GCR due to Earth's magnetic field with geomagnetic latitude and longitude. Figure 6a shows the absorbed dose rate in dependence on the geographical position for the year 2009 (solar minimum).

The magnetic field allows only particles of higher energies to penetrate at lower latitudes and as a consequence the lowest dose rates occur in the equatorial region. Figure $6 \mathrm{~b}$ presents the dose rates in the year 2013 at solar maximum conditions. During this period the dose rate caused by GCR had decreased due to the stronger interplanetary magnetic field. This effect is especially pronounced at higher geomagnetic latitudes. The solar cycle variations lead to a decrease in the daily average absorbed dose rate due to GCR from $160 \mu \mathrm{Gy} / \mathrm{d}$ (2009) to $145 \mu \mathrm{Gy} / \mathrm{d}$ (2013) (DOSTEL-2).

\subsubsection{ISS altitude influence on the absorbed dose rate of $S A A$}

Whereas the influence of the sun on the radiation environment constitutes a real natural phenomenon, another factor influencing the radiation load on board the ISS is to a certain extent under human control, namely the altitude of the ISS. The altitude of the ISS has increased since the beginning of the DOSIS experiment in 2009 from $335 \mathrm{~km}$ to $420 \mathrm{~km}$. Its influence on the contribution from GCR is negligible, but it strongly correlates with the dose contributions from the crossings of the SAA (see also Lishnevskii et al. 2012b).

The SAA resembles a cone like structure with the tip towards the ground. The cuts through the cone, i.e. the area of the SAA, increase with altitude thereby also increasing 
T. Berger et al.: DOSIS \& DOSIS 3D: DOSTEL radiation measurements on board the ISS
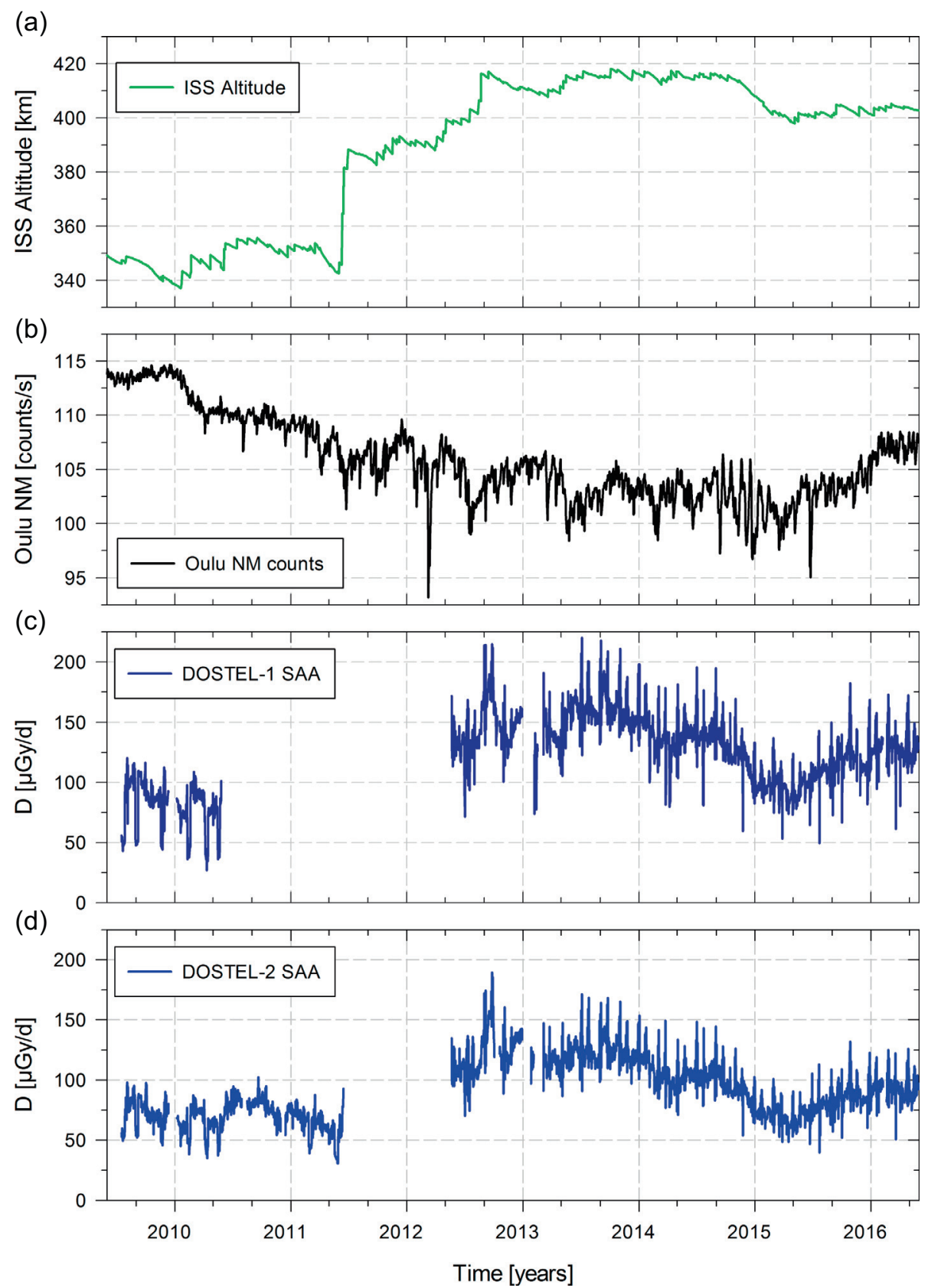

Fig. 7. (a) The changes of ISS altitude from June 2009 to June 2016; (b) the Oulu NM count rates from June 2009 to June 2016; (c, d) the measured daily absorbed dose rate for the contribution of the SAA for the DOSTEL-1 and DOSTEL-2 instruments. Note: No measurements were taken from June 2010 to May 2011.

the flight time of the ISS within the SAA. The main contributions to the SAA absorbed dose are from low energy protons and electrons, though inside the ISS the electrons are already shielded by the relevant hull of the spacecraft. Further on, the SAA proton contribution is strongly anisotropic (East/West anisotropy) resulting in more protons reaching the ISS from the west than from the east (Drobyshev \& Benghin 2011). Also, compared to GCR, the proton energies are rather low (a few tens to hundreds of $\mathrm{MeV}$ ), which results in a high variation of the SAA dose depending on the relevant local shielding environment inside the ISS (see also Figs. 10 and 11 of Berger et al. 2016).

In Figure 7 we provide therefore the ISS altitude (Fig. 7a) as well as the Oulu neutron monitor count rate (Fig. 7b) for the time period 06/2009-06/2016 covering the timeframe of the
DOSIS and DOSIS 3D experiments as well as the measured absorbed dose values from SAA crossings with the DOSTEL-1 instrument (Fig. 7c) and the DOSTEL-2 instrument (Fig. 7d). During the DOSIS experiment (05/2009-06/ 2011) the absorbed dose values for DOSTEL-1 were of the order of $125-90 \mu \mathrm{Gy} /$ day. The absorbed dose rates measured with DOSTEL-2 are always around $20 \%$ lower, which is due to (a) the different viewing directions of the DOSTEL-2 and also due to (b) different local shielding thicknesses of the detectors.

At the end of the DOSIS mission in June 2011 the ISS altitude was slowly raised from 340 to $390 \mathrm{~km}$ and this rise in altitude can still be seen in the DOSTEL-2 data (Fig. 7d) directly at the end of the mission. One year later in 2012 the station was at an altitude of $390 \mathrm{~km}$ and at almost $420 \mathrm{~km}$ 
(a)

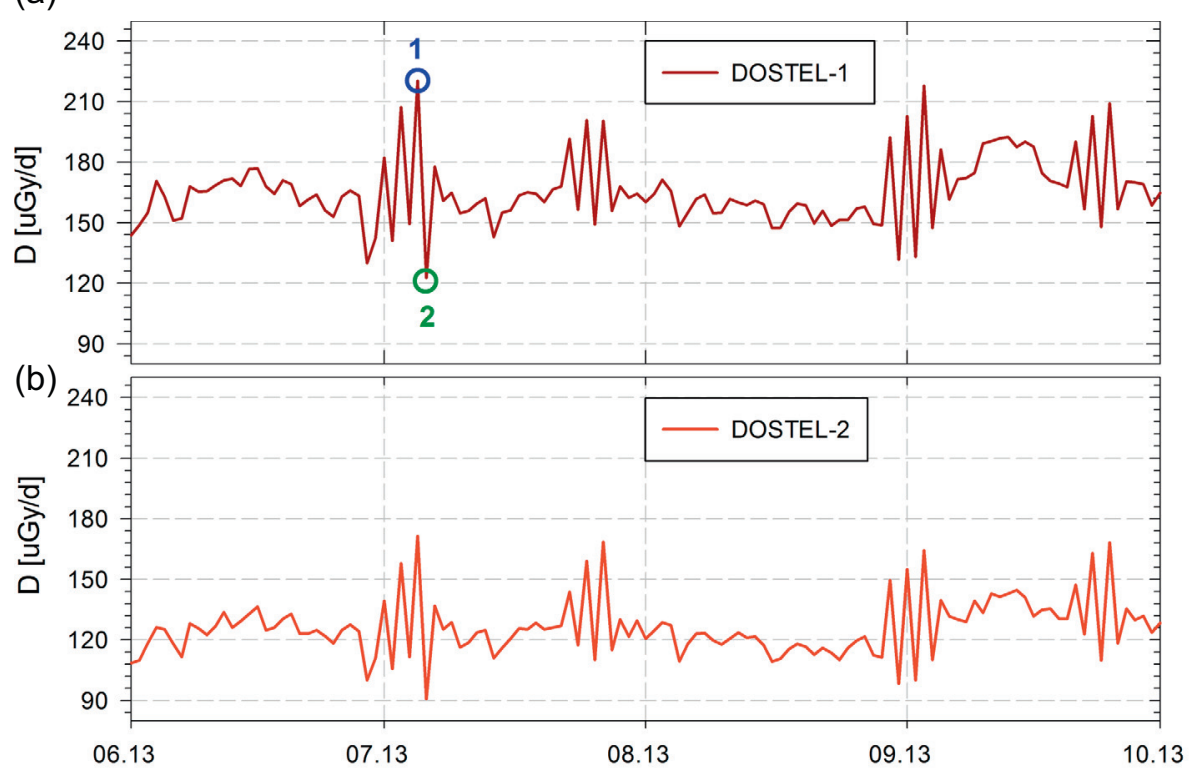

(c) Time [mm.yy]

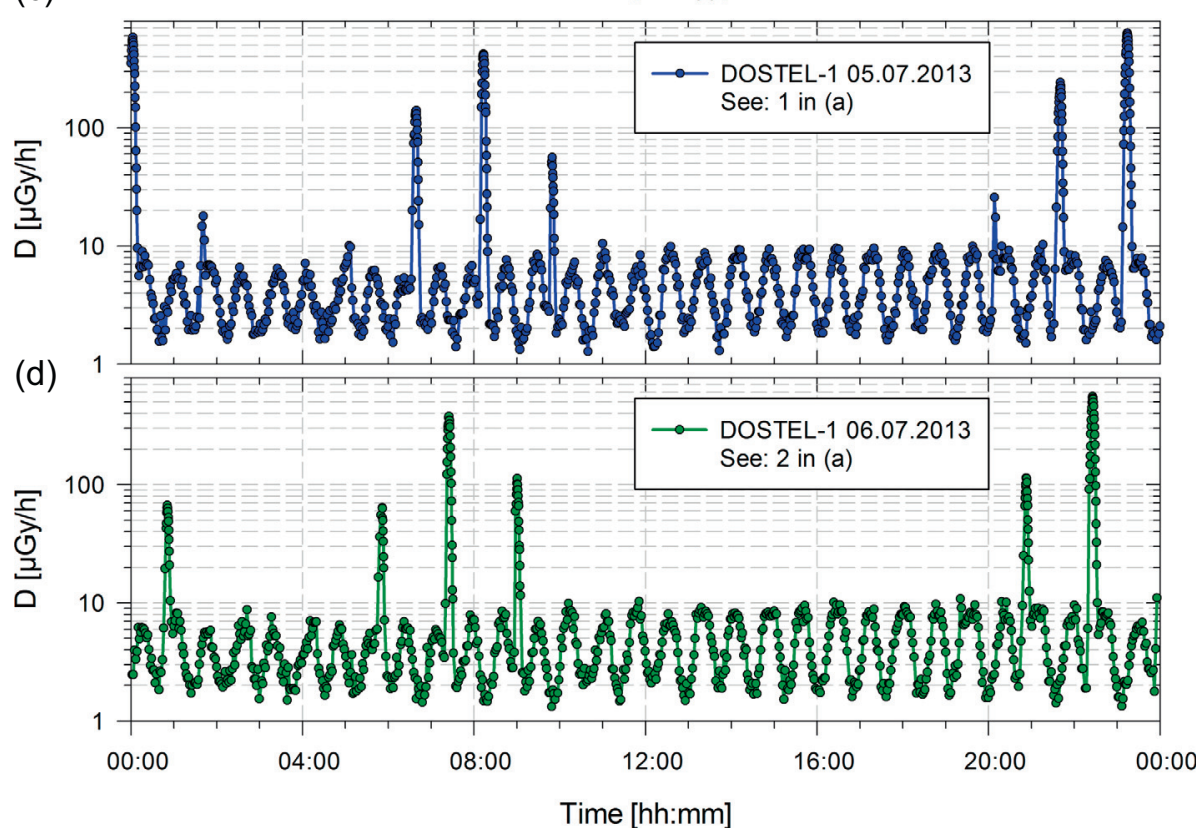

Fig. 8. (a) The bimonthly oscillation of the SAA dose measured with DOSTEL-1; (b) the bimonthly oscillation of the SAA dose measured with DOSTEL-2; (c) the hourly dose rate measured with DOSTEL-1 for July 05th 2013 having an SAA dose of $220 \mu \mathrm{Gy}$ and (d) the hourly dose rate measured with DOSTEL-1 for the following July 06th 2013 having an SAA dose of $123 \mu \mathrm{Gy} /$ day.

in the last quarter of 2012. Afterwards, the altitude has remained stable till the last quarter of 2014.

Within this time the absorbed dose rates measured by both DOSTEL instruments correlate nicely with the altitude changes - especially the 6-month long drop at the beginning of 2015 to around $400 \mathrm{~km}$ is perfectly reflected in both DOSTEL data. From the first quarter of 2015 onwards the station was at almost constant altitude, but we see another influence on the SAA dose, which is the decrease in solar activity as given in Figure $7 \mathrm{~b}$ reflected in an increase in the neutron monitor count rate and at the same time increasing the number of protons in the SAA.

Two further features of the daily SAA dose rate are worth looking in more detail. The first one are the in total six drops in SAA dose rate for DOSTEL-1 and eight drops in SAA dose for DOSTEL-2 during the DOSIS experiment phase, i.e. before 2012, which are related to attitude changes of the ISS and will be further discussed in Section 4.1.3.

The second feature, which can especially be seen clearly during the DOSIS 3D experiment in both DOSTEL instruments, are the oscillating spikes in the daily SAA dose rate over the whole mission duration. These spikes are correlated with the nominal orbits of the ISS. To further discuss this feature Figure 8 provides an in-depth analysis of the spikes. Figures $8 \mathrm{a}$ and $8 \mathrm{~b}$ show the daily SAA dose rate for the DOSTEL-1 and the DOSTEL-2 instruments over a timeframe of 4 months from June to the end of October 2013. As can 
(a)
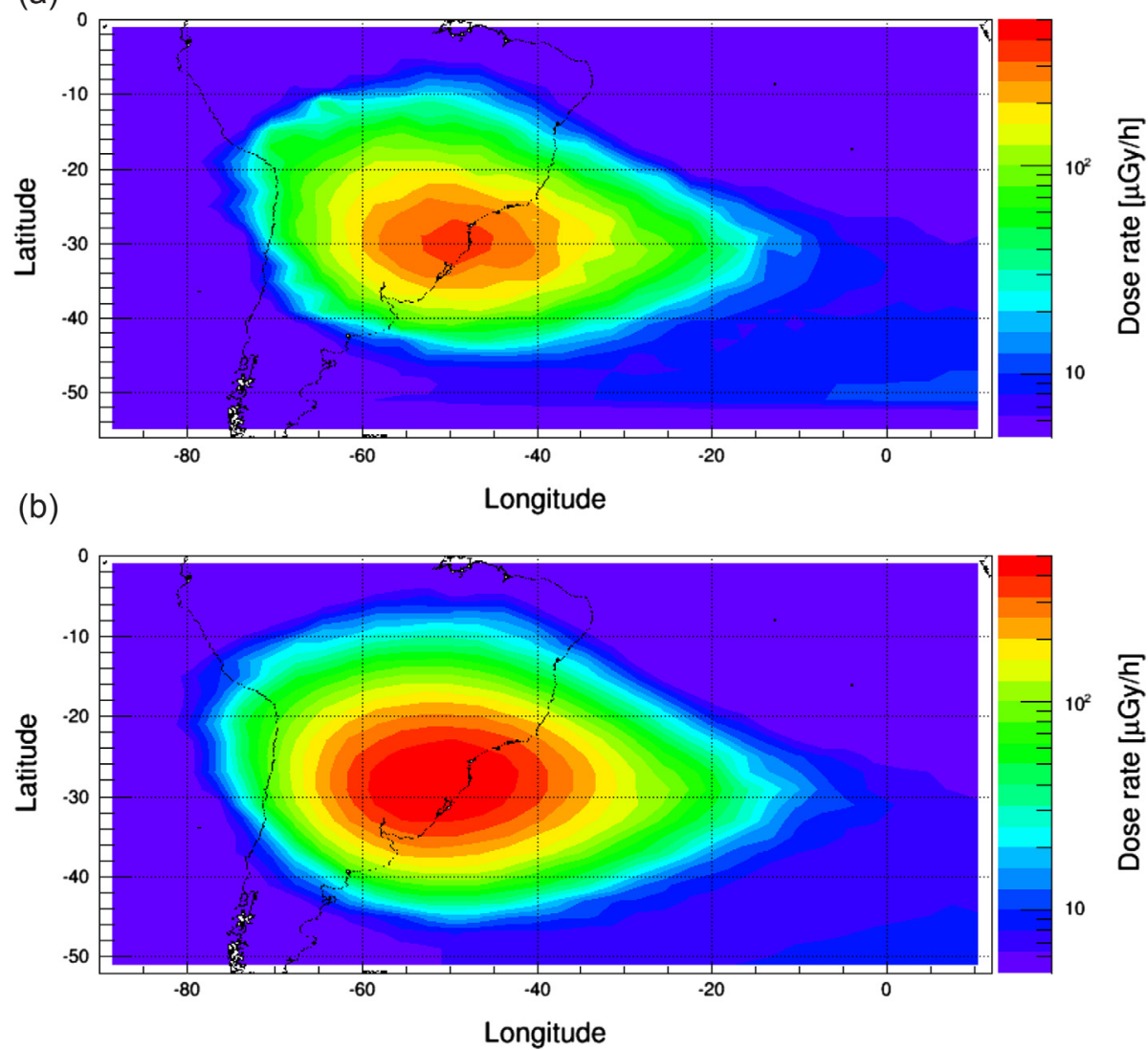

Fig. 9. The variation of the absorbed dose rate in logarithmic scale $(5 \mu \mathrm{Gy} / \mathrm{h}-500 \mu \mathrm{Gy} / \mathrm{h})$ for the illustration of the South Atlantic Anomaly (roughly between $10^{\circ} \mathrm{W}$ and $80^{\circ} \mathrm{W} ; 5^{\circ} \mathrm{S}$ and $45^{\circ} \mathrm{S}$ ): (a) for low ISS altitude (DOSIS year 2009: $\approx 350 \mathrm{~km}$ ) and (b) high ISS altitude (DOSIS 3D year 2013: $\approx 420 \mathrm{~km})$.

be seen, the dose rates correlate nicely over this timeframe and show a bimonthly oscillation pattern of 6 days. The reason behind this is that the ISS orbits Earth on average 15.54 times a day with an orbit time of $92.65 \mathrm{~min}$. Therefore the nominal ascending and descending SAA orbits (once a day ascending and once a day descending) shift slowly over time, so after a certain time period there are days where the SAA crossings happen over midnight - and this changes the total dose. To further illustrate this, we took the data from the maximum and the minimum of the SAA dose for the crossings at the beginning of July 2013 (Point 1 and Point 2 in Fig. 8a) and present them as dose rate per hour in Figure 8c for the July 05th and Figure 8d for the July 06th. Comparing the SAA crossings for these two days clearly shows that on July 05th we see in total nine spikes related to the crossing of the SAA while on July 06th the number of crossings is reduced to six. Since the daily absorbed dose is always calculated from midnight to midnight this leads to the high variation of daily dose for the SAA contribution $(220 \mu \mathrm{Gy} /$ day on July 05 th and $123 \mu \mathrm{Gy} /$ day on July 06th). The same behaviour was also observed by the TRITEL-RS instrument in the Zvezda module of the ISS (see references in Narici et al. 2015). This clearly indicates that both natural factors and human made changes of the station's altitude can lead to detectable variations of the radiation load on board the ISS.

For a better understanding of the changes in the SAA dose contribution, Figure 9 presents the SAA variation coupled to the ISS orbital data for two distinct time periods, namely the years 2009 and 2013. The influence of the ISS altitude $(\approx 350 \mathrm{~km}$ in 2009 and $\approx 420 \mathrm{~km}$ in 2013$)$ on the measured dose rate in the region of the SAA is clearly visible. As the station is lifted up to higher altitudes (Fig. 9b) it penetrates deeper into the inner radiation belt. This leads to higher count and dose rates. In the logarithmic scale of Figure 9 the latitudinal and longitudinal dependency of the measured dose rates during the crossings of the South Atlantic Anomaly (roughly between $10^{\circ} \mathrm{W}$ and $80^{\circ} \mathrm{W} ; 5^{\circ} \mathrm{S}$ and $45^{\circ} \mathrm{S}$ ) is resolved.

Figure 9a shows the dose rate in the SAA while the ISS was at altitudes of around $350 \mathrm{~km}$ during DOSIS in the year 2009 while Figure $9 \mathrm{~b}$ shows the dose rate for SAA crossings at altitudes of around $420 \mathrm{~km}$ during DOSIS 3D in the year 2013. The extended time spent in the SAA caused by the widening of the SAA at higher altitudes in combination with higher peak dose rates leads to an increase of the daily average absorbed dose rate from SAA crossings from $80 \mu \mathrm{Gy} / \mathrm{d}(2009$ at $350 \mathrm{~km})$ to $150 \mu \mathrm{Gy} / \mathrm{d}(2013$ at $420 \mathrm{~km})$.

\subsubsection{ISS attitude influence on the absorbed dose rate - the shuttle dockings}

As already shortly pointed out in Section 4.1.2 another influence on the radiation exposure is the attitude of the space station. In the nominal mode of the ISS flight direction (X) (red arrow in Fig. 10a) the Columbus Laboratory (red rectangle in Fig. 10a) is positioned at the forward right position of the ISS. At times when the Space Shuttle was still flying to the ISS the shuttle was docked at NODE-2 close to the Columbus 

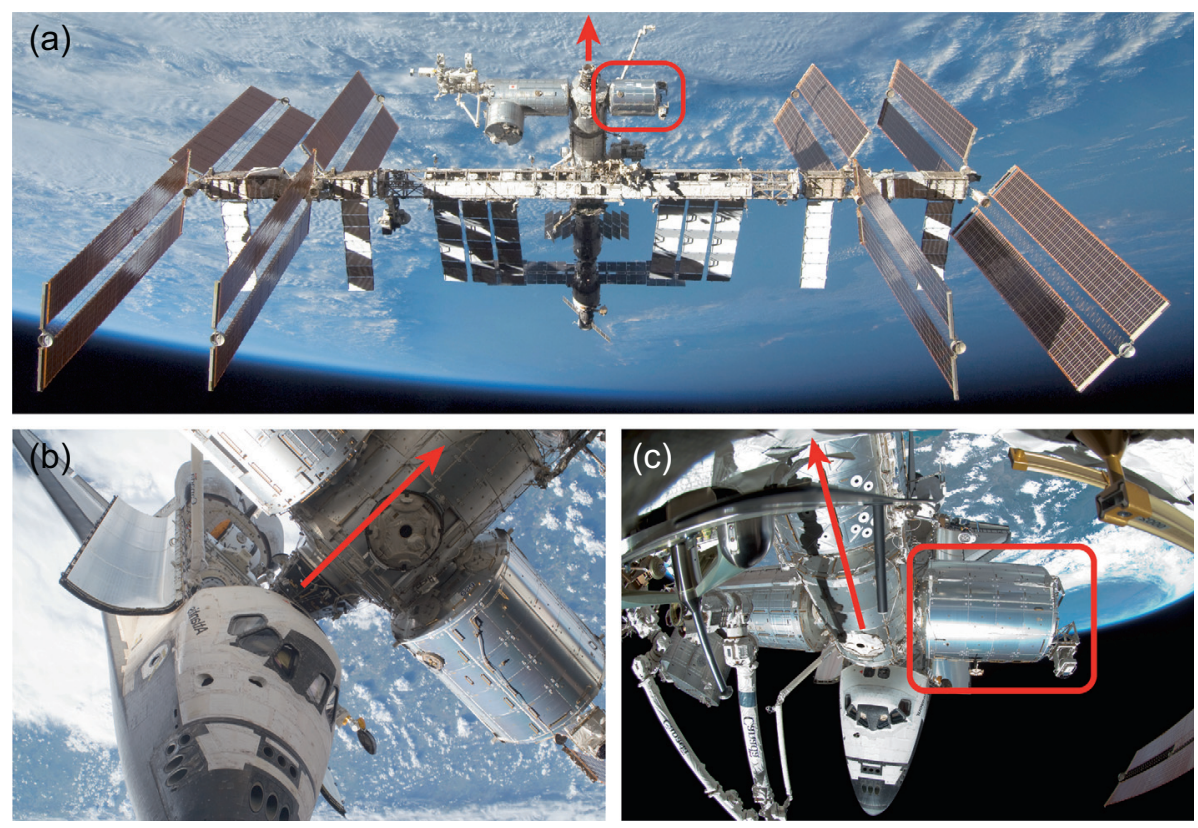

Fig. 10. (a) The ISS in nominal flight direction with the Columbus Laboratory at the front right position; (b) STS-132 Space Shuttle Atlantis docked to the ISS (picture taken on May 17th 2010); (c) STS-134 Space Shuttle Endeavour docked to the ISS (picture taken on May 27th 2011). Note: The relevant docking information is given in Table 4 column 1 \#6 and \#8. Source: NASA.

Table 4. Relevant shuttle dockings on the ISS during the DOSIS experiment timeframe.

\begin{tabular}{|c|c|c|c|c|c|c|c|c|}
\hline \# & Shuttle & Name & Launch & Landing & $\begin{array}{l}\text { Mission duration } \\
\text { [days] }\end{array}$ & $\begin{array}{l}\text { Docking to } \\
\text { ISS }\end{array}$ & $\begin{array}{c}\text { Undock from } \\
\text { ISS }\end{array}$ & $\begin{array}{r}\text { Docked } \\
\text { [days] }\end{array}$ \\
\hline 1 & STS-127 & Endeavour & $\begin{array}{l}15.07 .2009 \\
22: 03\end{array}$ & $\begin{array}{l}31.07 .2009 \\
14: 48\end{array}$ & 15.70 & $\begin{array}{l}17.07 .2009 \\
17: 47\end{array}$ & $\begin{array}{l}28.07 .2009 \\
17: 26\end{array}$ & 10.98 \\
\hline 2 & STS-128 & Discovery & $\begin{array}{l}29.08 .2009 \\
03: 59\end{array}$ & $\begin{array}{l}12.09 .2009 \\
19: 26\end{array}$ & 14.64 & $\begin{array}{l}31.08 .2009 \\
00: 54\end{array}$ & $\begin{array}{l}08.09 .2009 \\
19: 26\end{array}$ & 8.77 \\
\hline 3 & STS-129 & Atlantis & $\begin{array}{l}16.11 .2009 \\
19: 28\end{array}$ & $\begin{array}{l}27.11 .2009 \\
14: 44\end{array}$ & 10.80 & $\begin{array}{l}18.11 .2009 \\
15: 51\end{array}$ & $\begin{array}{l}25.11 .2009 \\
09: 53\end{array}$ & 6.75 \\
\hline 4 & STS-130 & Endeavour & $\begin{array}{l}08.02 .2010 \\
09: 14\end{array}$ & $\begin{array}{l}22.02 .2010 \\
03: 22\end{array}$ & 13.75 & $\begin{array}{l}10.02 .2010 \\
05: 05\end{array}$ & $\begin{array}{l}20.02 .2010 \\
00: 54\end{array}$ & 9.82 \\
\hline 5 & STS-131 & Discovery & $\begin{array}{l}05.04 .2010 \\
07: 44\end{array}$ & $\begin{array}{l}20.04 .2010 \\
13: 08\end{array}$ & 15.23 & $\begin{array}{l}07.04 .2010 \\
07: 44\end{array}$ & $\begin{array}{l}17.04 .2010 \\
12: 52\end{array}$ & 10.21 \\
\hline 6 & STS-132 & Atlantis & $\begin{array}{l}14.05 .2010 \\
18: 20\end{array}$ & $\begin{array}{l}26.05 .2010 \\
12: 48\end{array}$ & 11.79 & $\begin{array}{l}16.05 .2010 \\
14: 28\end{array}$ & $\begin{array}{l}23.05 .2010 \\
15: 22\end{array}$ & 7.04 \\
\hline 7 & STS-133 & Discovery & $\begin{array}{l}24.02 .2011 \\
21: 53\end{array}$ & $\begin{array}{l}09.03 .2011 \\
16: 57\end{array}$ & 12.79 & $\begin{array}{l}26.02 .2011 \\
19: 14\end{array}$ & $\begin{array}{l}07.03 .2011 \\
12: 00\end{array}$ & 8.69 \\
\hline 8 & STS-134 & Endeavour & $\begin{array}{l}16.05 .2011 \\
12: 57\end{array}$ & $\begin{array}{l}01.06 .2011 \\
06: 35\end{array}$ & 15.73 & $\begin{array}{l}18.05 .2011 \\
10: 14\end{array}$ & $\begin{array}{l}30.05 .2011 \\
03: 55\end{array}$ & 11.73 \\
\hline
\end{tabular}

Laboratory. To avoid damage of the shuttle the ISS was rotated by $180^{\circ}$ during the time the shuttle was docked to the ISS, thereby putting the Columbus Laboratory on the backward left position with the Shuttle attached to its back end. Figure 10 shows two examples of shuttles docked to the ISS in the years 2010 (STS-132) (Fig. 10b) and 2011 (STS-134) (Fig. 10c). The shuttle fleet retired with the last shuttle mission being STS-135 (Atlantis) leaving the space station on July 19th 2011 bringing back the DOSIS-MAIN-BOX including the DOSTEL-2 and the DDPU for refurbishment (see also Sect. 2.2).

The relevant Shuttle missions and timelines such as launch, landing, docking to and undocking from the ISS, as well as the docking duration, are provided in Table 4 . The docking of the shuttle has two impacts on the absorbed dose measurements. The first one is the rotation of the ISS by $180^{\circ}$. This influences the dose contributions from the SAA due to the fact that the radiation field in the SAA is strongly anisotropic. Further on, the local shielding for detectors positioned inside the station changes due to the rotation of the ISS (as mentioned Columbus goes from forward right to backward left) (Drobyshev \& Benghin 2011). The mass of the shuttle (around 78 tons) increases the local shielding for detectors close to the shuttle (Dachev et al. 2011), which is also the case for the DOSTEL instruments in Columbus.

Figure 11 provides the absorbed dose rates for the SAA measured by the DOSTEL-1 (Fig. 11a) and the DOSTEL-2 (Fig. 11b) instruments and correlates them to the relevant shuttle dockings as given in Table 4. In 2009 and 2010 DOSTEL-1 and DOSTEL-2 measured six shuttle dockings; DOSTEL-2 additionally provided data for shuttle dockings \#7 and \#8 in the year 2011 . 
(a)

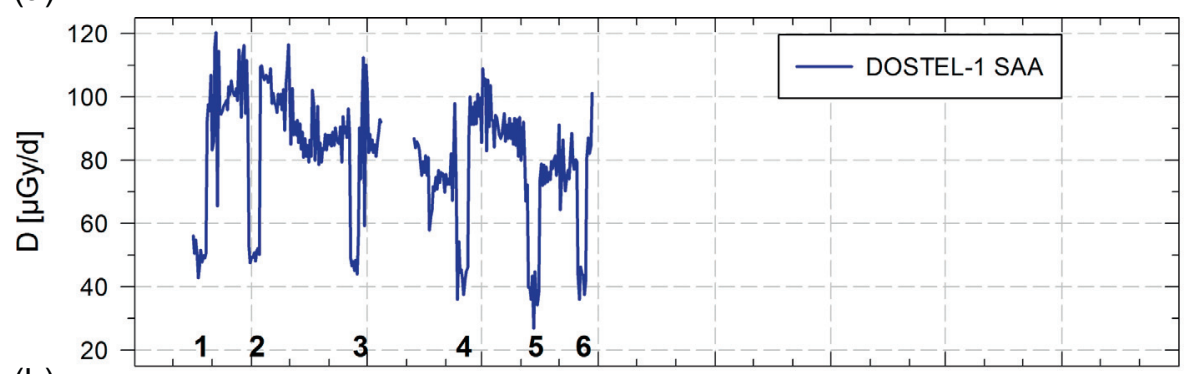

(b)

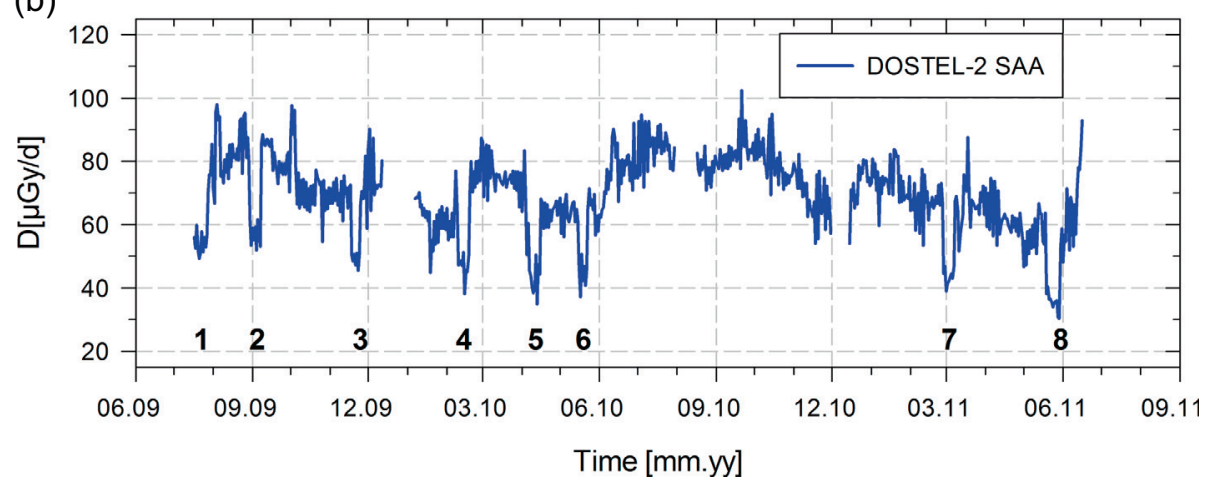

Fig. 11. Variation of the absorbed dose contribution for SAA crossings measured during the DOSIS experiment for (a) DOSTEL-1 and (b) DOSTEL-2. The relevant numbers 1-8 relate to in total eight Shuttle dockings performed during the DOSIS experiment phase (see also Table 4).
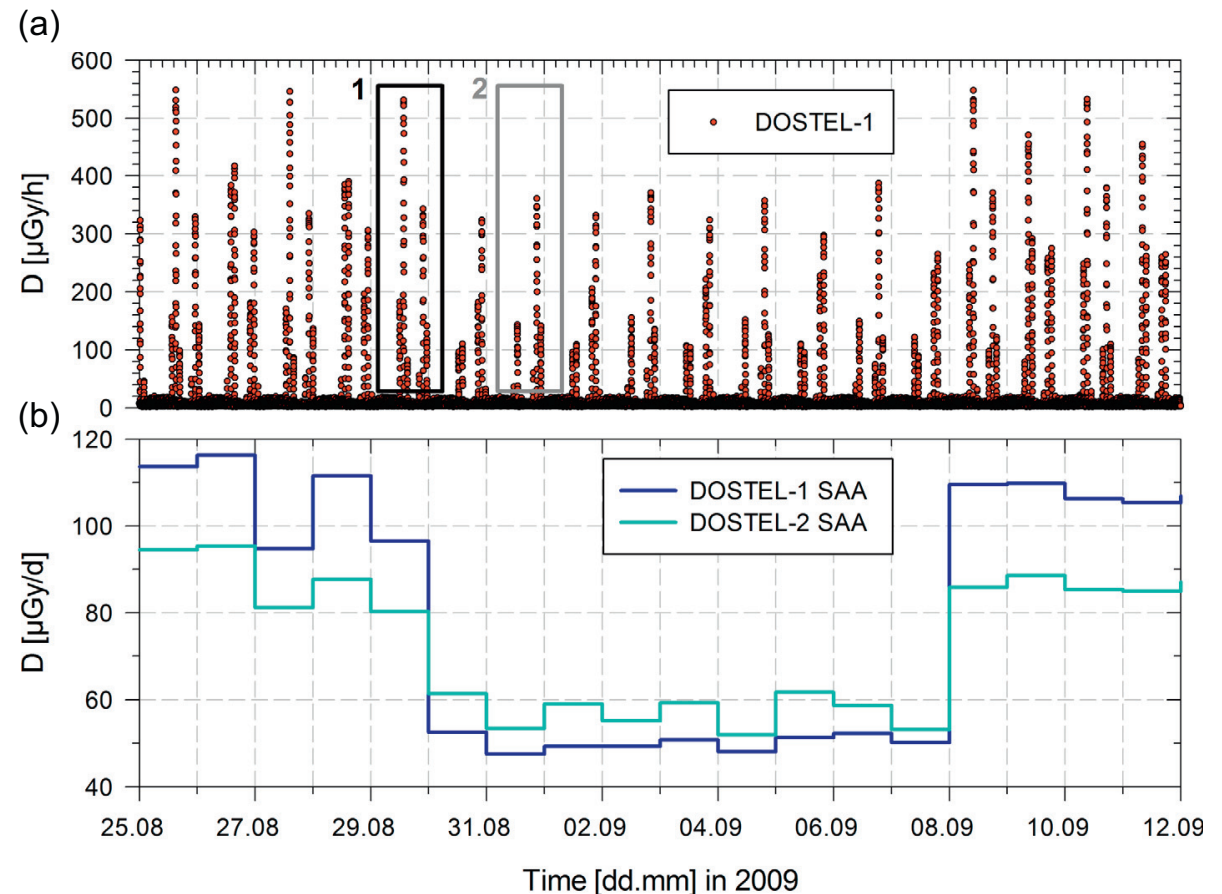

Fig. 12. (a) The dose rate measured with the DOSTEL-1 instrument over the timeframe of the 2nd Shuttle docking (see Table 4); (b) the daily average of the SAA dose rate for the DOSTEL-1 and the DOSTEL-2 instruments for this respective Shuttle docking.

As seen in Figure 11 the measurements during DOSIS started while the first shuttle STS-127 was still docked to the ISS. After undocking the absorbed dose values increased (by more than a factor of 2 for the DOSTEL- 1 as well as for the DOSTEL-2). This behaviour is seen for all following dockings of the Shuttle to the ISS in the years 2009-2011. To further discuss the influence of the docking on the absorbed dose values we took the 2 nd Shuttle mission during the DOSIS experiment (STS-128) which was docked to the ISS from August 31st (00:54) to September 08th 2009 (19:26) for 8.77 days as an example with relevant data provided in Figure 12.

Figure $12 \mathrm{a}$ shows the hourly total absorbed dose rate measured with the DOSTEL-1 instrument from August 25th till September 12th 2009 with the shuttle docking occurring from August 31st to September 08th. Figure 12b shows the 


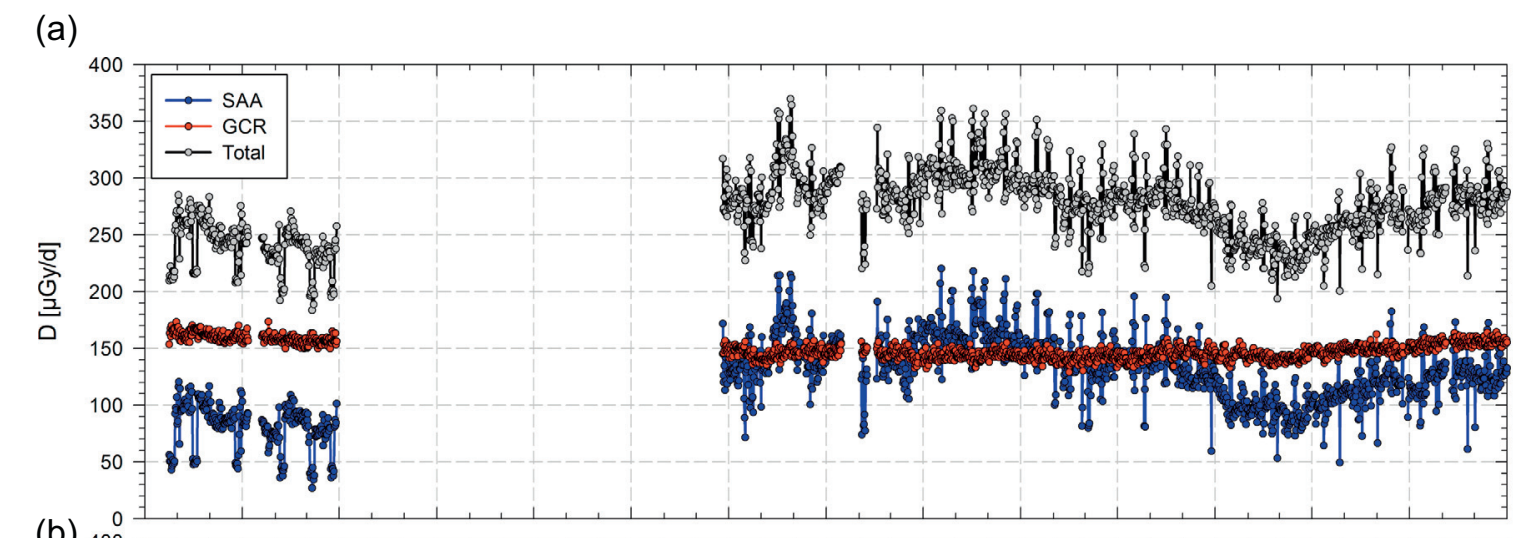

(b) 400

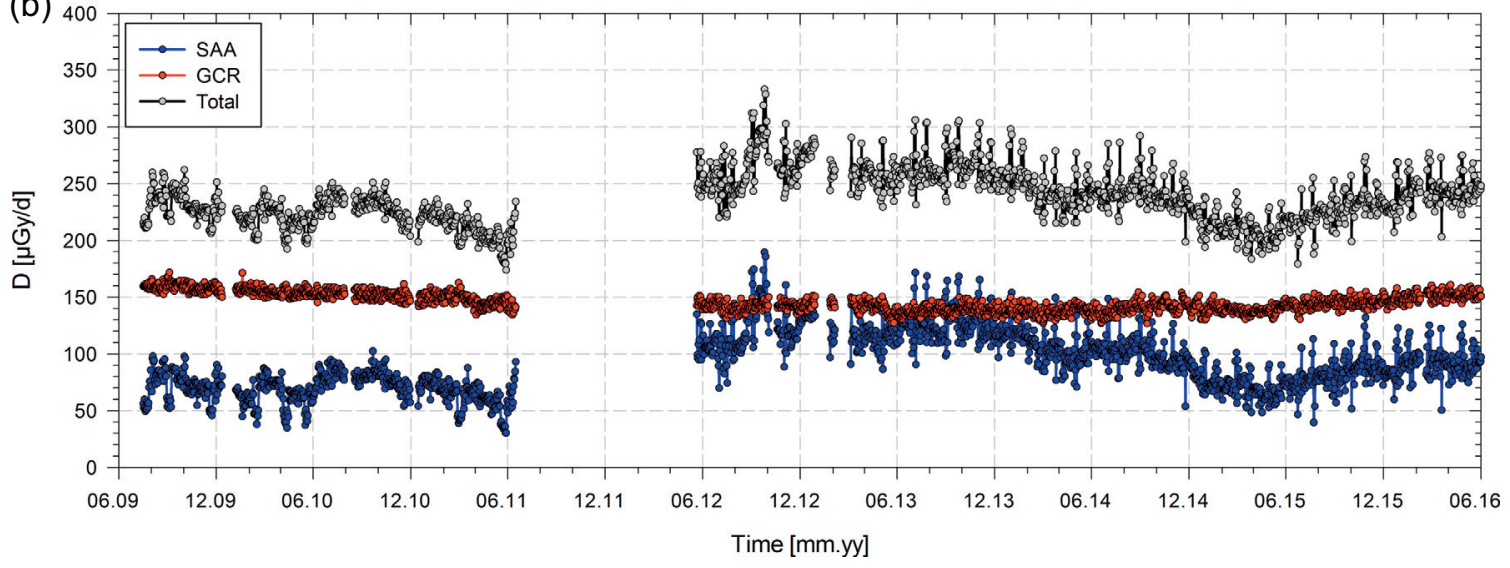

Fig. 13. Daily absorbed dose rates measured by DOSTEL-1 (a) and DOSTEL-2 (b) instruments. The contribution of the absorbed dose rates measured in the region of the South Atlantic Anomaly is given in blue, while Galactic Cosmic Ray contribution is provided in red. Grey gives the total absorbed dose rate as the sum of the GCR and SAA contributions. Note: No measurements were taken from June 2010 to May 2011.

daily absorbed dose rates for SAA crossings for both the DOSTEL-1 and the DOSTEL-2 instruments. We can observe that for both DOSTEL instruments the SAA dose contribution drops by around $50 \%$ during the time the shuttle was docked to the ISS (Fig. 12b). Looking at Figure 12a we see that the hourly absorbed dose rate for SAA changes as soon as the shuttle is docked. For a comparison we focus on the two ways the ISS crosses the SAA (descending and ascending orbits). The black rectangle (1 in Fig. 12a) provides a summary of first descending orbits and second ascending orbits for the time before the shuttle docking. The same (descending and ascending) orbits are given in the grey rectangle ( 2 in Fig. 12a) for the time of the shuttle docking. The absorbed dose rate for the descending orbits changes from almost $550 \mu \mathrm{Gy} / \mathrm{h}$ (peak value) without shuttle to around $150 \mu \mathrm{Gy} / \mathrm{h}$ (peak value) during the shuttle docking. Therefore the absorbed dose for one "main" crossing of the SAA during descending orbits changes from $\sim 45 \mu \mathrm{Gy}$ to $\sim 15 \mu \mathrm{Gy}$, which is a reduction by a factor of 3 . In comparison to this the hourly dose rate for the ascending orbits with maximum of $310 \mu \mathrm{Gy} / \mathrm{h}$ increases to values of around $350 \mu \mathrm{Gy} / \mathrm{h}$, which leads to an increase in dose for a "main" SAA crossing from $\sim 22$ to $\sim 26 \mu \mathrm{Gy}$. In total the daily absorbed dose being the sum of the descending and ascending orbits decreases by a factor of 2 .

Similar behaviour was observed by the Russian DB-8 (silicon detector) instruments positioned in the Zvezda module of station (see Fig. 4 in Drobyshev \& Benghin 2011) during various shuttle dockings which clearly indicates that the rotation of the ISS and the thereby changed (a) viewing direction of the instrument and (b) local shielding influences the dose due of the SAA crossings. Measurements have also been performed outside the ISS with the R3D3 instrument on the European Technology Exposure Facility (EuTEF) platform of Columbus (Dachev et al. 2011, 2012) which showed drops of the absorbed dose rate from 1400 to $\sim 600 \mu \mathrm{Gy} / \mathrm{h}$ during shuttle dockings. The higher dose rate is of course due to the very low shielding of the R3D3 detector positioned outside the station.

Concerning the changes in the GCR environment, it was observed that for the DOSTEL instruments the overall count rate for GCR was increased during the shuttle docking, which can be attributed to the higher local shielding due to the shuttle and thereby the higher generation of secondary particles which contribute to the GCR count rate. The absorbed dose values for the GCR are only slightly increased.

With all this information it can be concluded that the ISS attitude change is the main reason for the change in the SAA dose rate during the Shuttle dockings.

\subsection{Absorbed dose}

After the relevant influences on the radiation environment onboard the ISS the following section focuses on the presentation and interpretation (based on results and conclusions from Sects. 4.1.1 to 4.1.3) of the total absorbed dose values measured during the DOSIS and DOSIS 3D experiment phases with both DOSTEL instruments.

Figure 13 provides the absorbed dose rates in $\mu \mathrm{Gy} /$ day for the DOSTEL-1 instrument (Fig. 13a) and the DOSTEL-2 instrument (Fig. 13b). The absorbed dose values are separated for the GCR component (in red), for the SAA contributions (in blue) as well as for the total absorbed dose (in grey) being the sum of the two mentioned before. Absorbed dose values are 
(a)

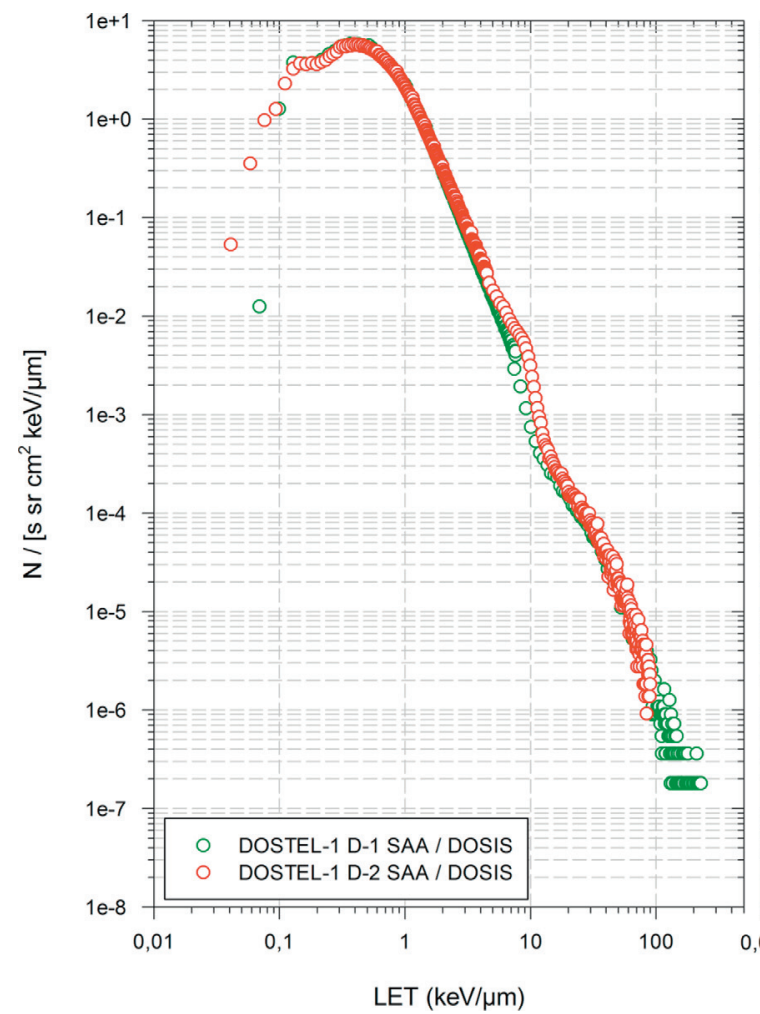

(b)

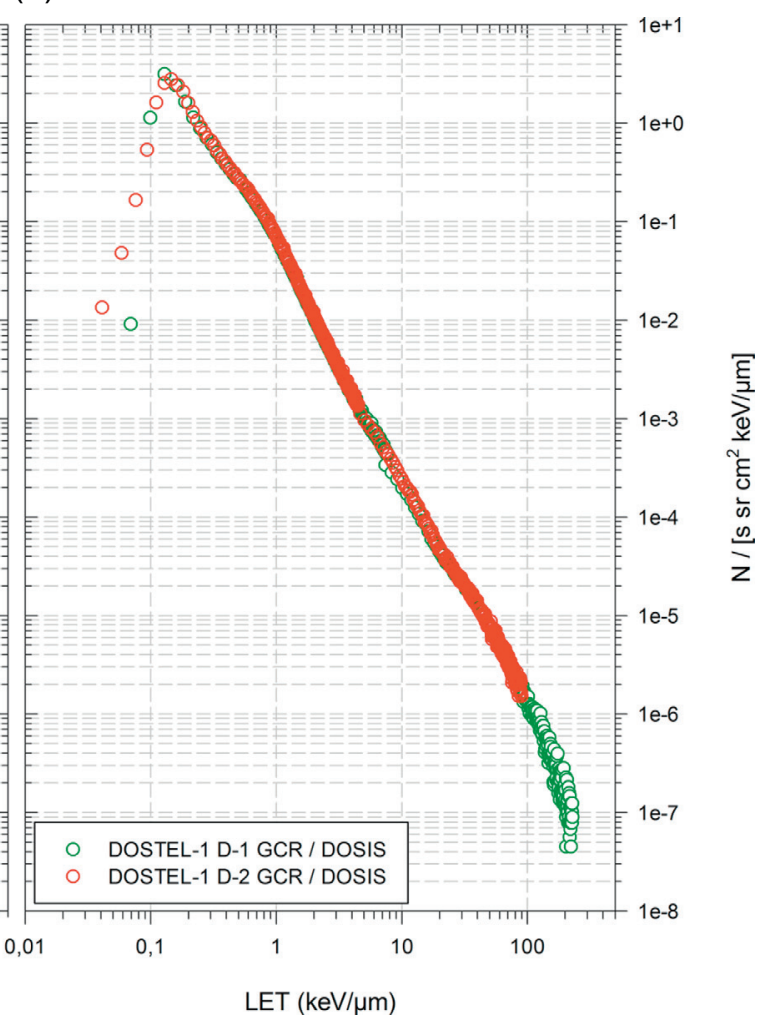

Fig. 14. Averaged LET spectrum taken by DOSTEL-1 during the DOSIS experiment (a) SAA and (b) GCR.

given for the DOSIS experiment from $18 / 07 / 2009$ to $20 / 05$ / 2010 for the DOSTEL-1 instrument and from 18/07/2010 to $16 / 06 / 2011$ for the DOSTEL-2 instruments. For the DOSIS $3 \mathrm{D}$ experiment data is shown from the activation of the experiment at 21/05/2012 up to $31 / 05 / 2016$.

The total absorbed dose values follow the solar cycle modulation as discussed in Sections 4.1.1-4.1.3; the variations of the ISS altitude and the attitude changes during Space Shuttle dockings. Values of up to $280 \mu \mathrm{Gy} /$ day were measured by DOSTEL-1 at the beginning of the DOSIS experiment phase in 2009; the values decreased to $250 \mu \mathrm{Gy} /$ day at the end of DOSTEL-1 measurement time period in May 2010. During the shuttle docking the total absorbed dose decreased to daily values close to $180 \mu \mathrm{Gy} /$ day. With the beginning of DOSIS 3D (and at higher altitudes) we reached absorbed daily dose values on single days of up to $370 \mu \mathrm{Gy} /$ day which were further modulated during the solar cycle and due to altitude variations leading to values of $280 \mu \mathrm{Gy} /$ day at the end of May 2016.

Looking at the relative contributions from the SAA and the GCR to the total absorbed dose we can see that during the DOSIS mission the GCR contribution is on average $65 \%$ with a $35 \%$ contribution of the SAA. During shuttle dockings these values change to $80 \%$ GCR and $20 \%$ SAA contributions. During DOSIS 3D when the ISS was at higher altitudes GCR and SAA contributed almost equally to the total absorbed dose. This ratio slowly changed (especially in the year 2015) due to the influence of ISS altitude decrease $(60 \%$ GCR and $40 \%$ SAA) but goes back to around equal contributions at the end of May 2016 due to the decrease of solar activity. The differences between the DOSTEL-1 and DOSTEL-2 instruments are mostly related to the lower SAA dose in DOSTEL-2 (see also Sect. 4.1.2) caused by the different local shielding environment.

\subsection{LET spectra}

To determine dose equivalents (cf. Sect. 4.4) we need to determine the average quality factor $Q$ for the GCR and the SAA components of the radiation field onboard the ISS. The average $Q$ is calculated from the LET spectrum which is measured with the DOSTEL instruments in the coincidence mode (see also Sect. 3.1) using a mean incident angle of $30^{\circ}$ which corresponds to an average path length of $364 \mu \mathrm{m}$ in a single detector plane. Figure 14 shows the differential LET spectra for the SAA (Fig. 14a) and the GCR (Fig. 14b) contributions for the DOSTEL-1 instrument measured during the DOSIS missions.

The LET spectra are given for both detectors (D-1, top) and (D-2, bottom) of the DOSTEL-1 instrument. As previously discussed in Section 3.2, D-1 and D-2 have different gain factors which lead to a higher resolution in the low LET range for D-2 and a higher upper LET threshold for D-1. Nevertheless, the comparison of the two spectra shows almost identical data over the LET region covered by both detectors. Therefore for all further analysis the D-1 LET spectrum (with the higher upper LET threshold) is used for the determination of the average $Q$. The average $Q$ for the SAA contributions (dominated by low energy protons) is 1.22 while the average $Q$ for the GCR contributions is 3.20 .

Figure 15 compares the LET spectra for the DOSIS and the DOSIS 3D missions for the SAA contribution (Fig. 15a) and the GCR contributions (Fig. 15b). We can observe an increase in the SAA LET spectra due to the increase in ISS altitude as 
(a)

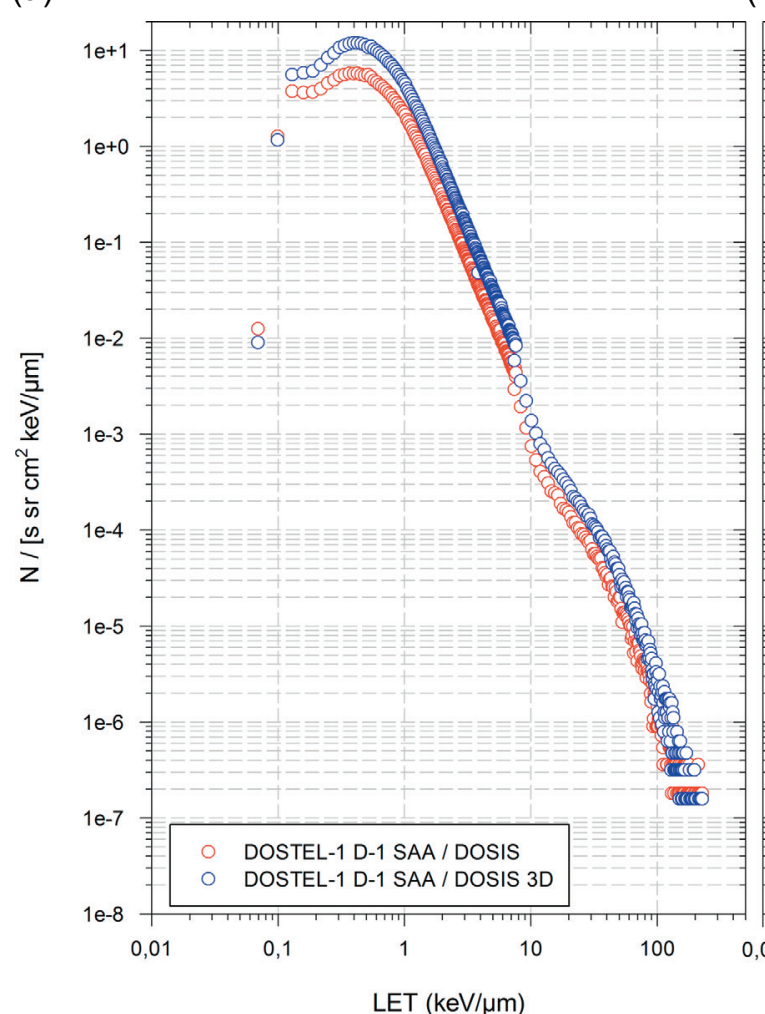

(b)

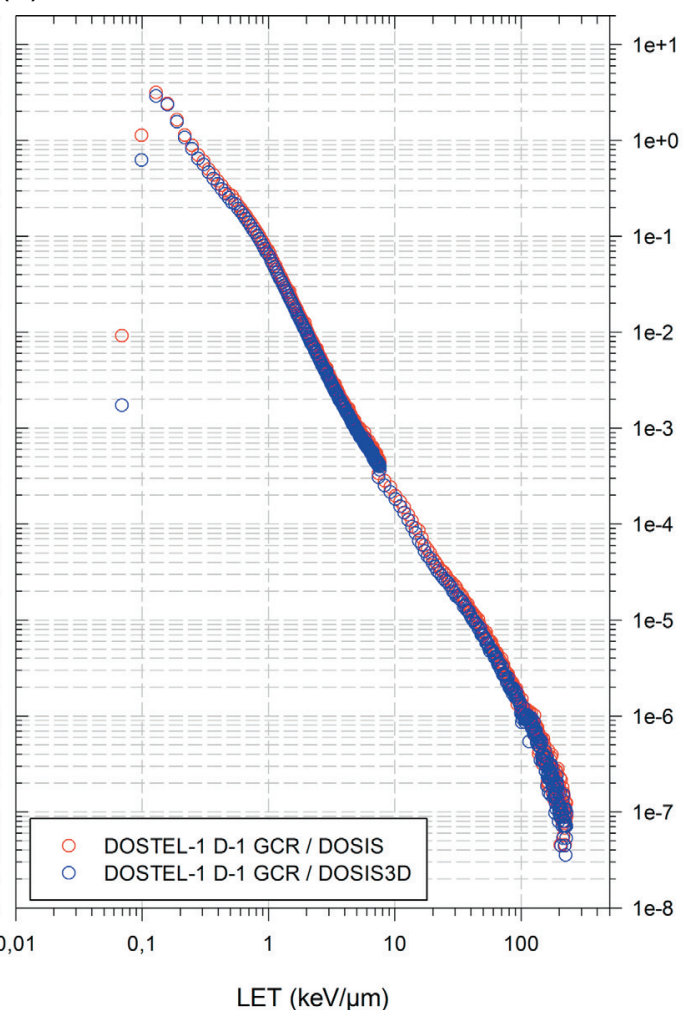

Fig. 15. Averaged LET spectrum taken by DOSTEL-1 during the DOSIS and DOSIS 3D experiments (a) SAA and (b) GCR.

(a)
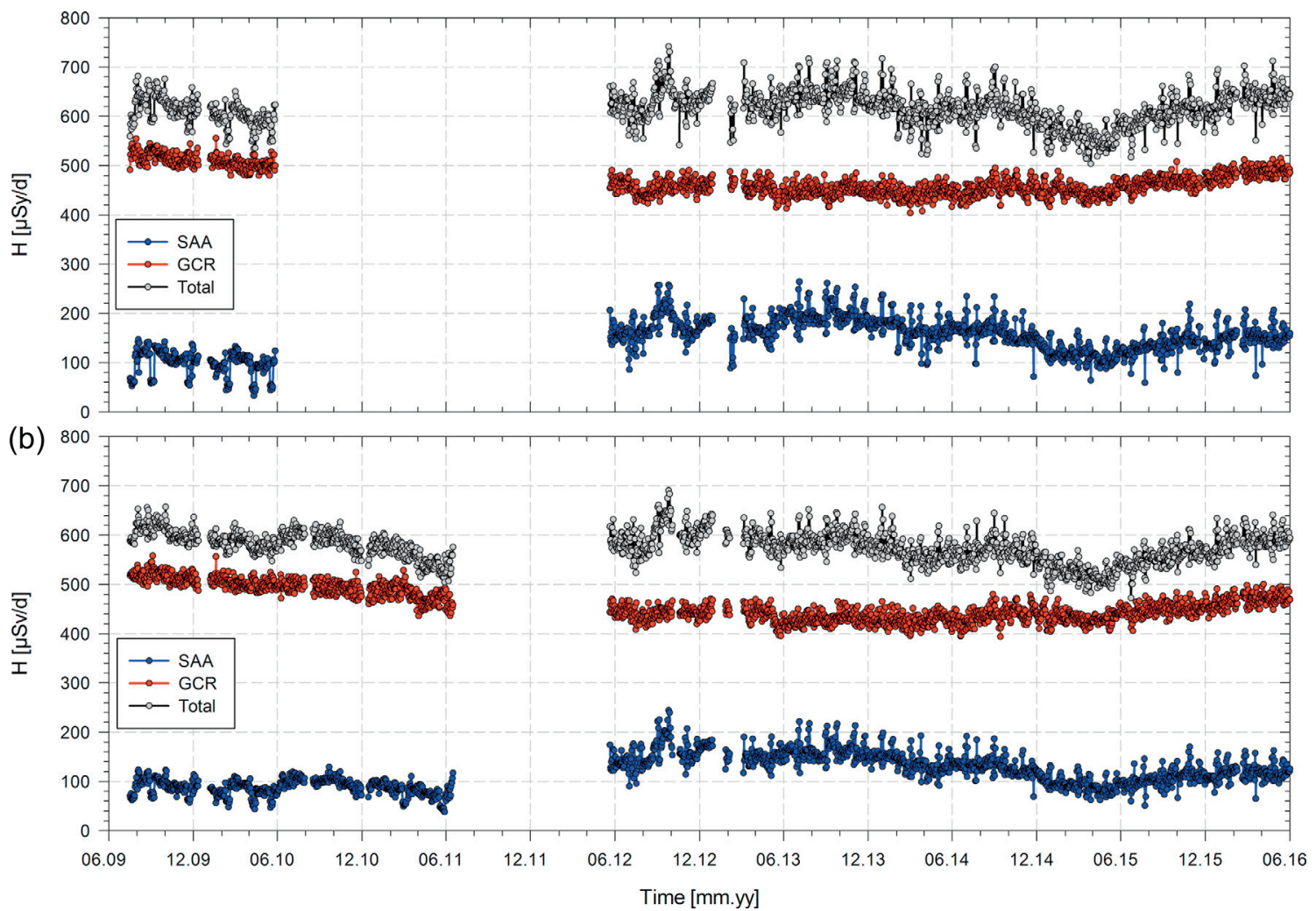

Fig. 16. Daily dose equivalent rate measured by DOSTEL-1 (a) and DOSTEL-2 (b) instruments. The dose equivalent rate is calculated with the mean quality factor $Q$ from the measured LET spectra. The contributions of dose equivalent rates measured in the region of the South Atlantic Anomaly and for Galactic Cosmic Ray contributions as well as the total dose equivalent rate are shown separately. Note: No measurements were taken from June 2010 to May 2011. 
T. Berger et al.: DOSIS \& DOSIS 3D: DOSTEL radiation measurements on board the ISS

Table 5. Comparison of daily dose rate $\left(\right.$ in $\mathrm{H}_{2} \mathrm{O}$ ) measured with the DOSTEL-1 and the NASA-TEPC for a five-day time period in 2014 (NASA-TEPC data from Kroupa et al. 2015).

\begin{tabular}{ccc}
\hline \hline Date & \multicolumn{2}{c}{ Absorbed dose rate $[\mu \mathrm{Gy} / \mathrm{d}]$} \\
\cline { 2 - 3 } & DOSTEL-1 & NASA-TEPC \\
\hline 01.01 .2014 & 272 & 295 \\
02.01 .2014 & 341 & 370 \\
03.01 .2014 & 276 & 297 \\
04.01 .2014 & 303 & 320 \\
05.01 .2014 & 295 & 321 \\
\hline
\end{tabular}

Table 6. Comparison of dose rates measured with the DOSTEL-1 and the DOSTEL-2 instruments with data from ${ }^{7} \mathrm{LiF}: \mathrm{Mg}$, Ti thermoluminescence detectors for all relevant DOSIS and DOSIS 3D mission phases.

\begin{tabular}{|c|c|c|c|c|c|c|}
\hline \multirow[t]{2}{*}{ Experiment } & \multirow[t]{2}{*}{ Phase } & \multirow[t]{2}{*}{ Duration } & \multirow[t]{2}{*}{ ISS altitude $[\mathrm{km}]$} & DOSTEL-1 & DOSTEL-2 & ${ }^{7} \mathrm{LiF}: \mathrm{Mg}, \mathrm{Ti}$ \\
\hline & & & & \multicolumn{3}{|c|}{ Absorbed dose rate $[\mu \mathrm{Gy} / \mathrm{d}]$} \\
\hline \multirow[t]{2}{*}{ DOSIS } & 1 & July 15, 2009-November 27, 2009 & $339-348$ & $248 \pm 20$ & $231 \pm 12$ & $261 \pm 21$ \\
\hline & 2 & November 16, 2009-May 26, 2010 & $337-349$ & $234 \pm 18$ & $219 \pm 11$ & $238 \pm 10$ \\
\hline \multirow[t]{8}{*}{ DOSIS 3D } & 1 & May 15, 2012-September 17, 2012 & $397-417$ & $286 \pm 25$ & $256 \pm 21$ & $311 \pm 9$ \\
\hline & 2 & October 23, 2012-March 16, 2013 & $407-416$ & $288 \pm 20$ & $267 \pm 13$ & $281 \pm 9$ \\
\hline & 3 & March 28, 2013-September 11, 2013 & $407-416$ & $297 \pm 23$ & $259 \pm 13$ & $294 \pm 7$ \\
\hline & 4 & September 25, 2013-March 11, 2014 & $413-418$ & $294 \pm 23$ & $256 \pm 17$ & $294 \pm 12$ \\
\hline & 5 & March 25, 2014-September 09, 2014 & $413-417$ & $279 \pm 22$ & $241 \pm 13$ & $262 \pm 7$ \\
\hline & 6 & September 26, 2014-March 12, 2015 & $401-416$ & $256 \pm 20$ & $224 \pm 14$ & $256 \pm 7$ \\
\hline & 7 & March 27, 2015-December 11, 2015 & $398-405$ & $254 \pm 20$ & $221 \pm 15$ & $237 \pm 7$ \\
\hline & 8 & December 15, 2015-June 18, 2016 & $401-405$ & $282 \pm 19$ & $243 \pm 14$ & $263 \pm 11$ \\
\hline
\end{tabular}

Note. Data from ${ }^{7} \mathrm{LiF}: \mathrm{Mg}$,Ti detectors is taken as average from the results from DLR, ATI, SCK•CEN, MTA EK and IFJ.

described in Section 4.1.2. The GCR spectra show a slight decrease of particles over the whole LET range which is due to the increase in solar activity from DOSIS to DOSIS 3D. The relevant $Q$ for SAA changed from 1.22 to 1.20 from DOSIS to DOSIS 3D while the $Q$ values for the GCR component slightly decreased from 3.20 to 3.13 .

\subsection{Dose equivalent}

Based on the data given in Section 4.2 for the absorbed dose and the relevant average $Q$ provided in Section 4.3 we can now determine the dose equivalent values for the two DOSTEL instruments for the DOSIS and DOSIS 3D missions. Figure 16 provides the dose equivalent rates in $\mu$ Sy/day for the DOSTEL-1 instrument (Fig. 16a) and the DOSTEL-2 instrument (Fig. 16b). It shows the dose equivalent values separated for the GCR component (in red), the SAA contributions (in blue) as well as for the total dose equivalent (in grey) being the sum of the two. Dose equivalent values are given (as in Fig. 13) for the DOSIS experiment from 18/07/2009 to $20 / 05 / 2010$ for the DOSTEL-1 instrument and from $18 / 07 / 2010$ to $16 / 06 / 2011$ for the DOSTEL-2 instrument. For the DOSIS 3D experiment data is given from the activation of the experiment $21 / 05 / 2012$ up to $31 / 05 / 2016$.

While for the absorbed dose the ratio of GCR/SAA contributions was $65 \%-35 \%$ for the DOSIS missions this ratio changed due to the different quality factors related to the SAA and the GCR contributions. During DOSIS (DOSTEL-1) we observed SAA dose equivalent rates of up to $150 \mu \mathrm{Sv} /$ day with GCR dose equivalent rates of more than $550 \mu \mathrm{Sv} /$ day which shifts the contribution from the GCR component to the total dose equivalent to almost $80 \%$ while the SAA components account only for $20 \%$. Of course all variations due to solar cycle influence, ISS altitude changes and Shuttle dockings (as discussed already for the absorbed dose rates in Sect. 4.2) are mirrored also in the dose equivalent. At the end of May 2016 the DOSTEL-1 instrument measured a total dose equivalent rate of $647 \mu \mathrm{Sv} /$ day $(492 \mu \mathrm{Sv} /$ day for GCR and $154 \mu \mathrm{Sv} /$ day for SAA) while the DOSTEL-2 instrument measured $591 \mu \mathrm{Sv} /$ day $(471 \mu \mathrm{Sv} /$ day for GCR and $120 \mu \mathrm{Sv} /$ day for SAA).

\subsection{Results in comparison with other radiation detectors onboard the ISS}

Several other active radiation detectors measured during the time period of the DOSIS and DOSIS 3D experiments (see also Narici et al. 2015). We only want to show some baseline comparison in order to bring the measurements performed with the DOSTEL instruments in an overall ISS perspective. For example, four silicon detectors (DB-8) are used for operational dosimetry in the Russian Zvezda module (Lishnevskii et al. 2010, 2012a, 2012b). These units are at distinct positions with various average shielding thicknesses and provide absorbed dose values in silicon for GCR and SAA contributions separately. The DB- 8 instruments measured a contribution of GCR for the year 2009 of up to $110 \mu \mathrm{Gy} /$ day (in silicon) while the contributions from SAA ranged from $100 \mu \mathrm{Gy} /$ day to over $300 \mu \mathrm{Gy} /$ day (in silicon) depending on the detector location. Taking into account, that the measuring range of the DB- 8 goes up to an energy deposition of $\sim 20 \mathrm{MeV}$ in silicon the measured dose rates are comparable with those of the DOSTEL-1 instruments for GCR which measured up to $130 \mu \mathrm{Gy} /$ day (in silicon) with an energy deposition range of up to $165 \mathrm{MeV}$. The SAA contributions measured with the DOSTEL instruments of up to $80 \mu \mathrm{Gy} /$ day 
(in silicon) are comparable to the lowest values of the DB-8 which indicate that the DOSTEL instruments in Columbus are heavier shielded than the DB-8 units in Zvezda. This heavier shielding also increases the GCR contribution to the DOSTEL dose.

A further comparison is provided in Table 5 with measurements performed with the NASA Tissue Equivalent Proportional Counter (NASA-TEPC) at the beginning of 2014 (Kroupa et al. 2015). Table 5 provides the total absorbed dose rates for five consecutive days measured with the DOSTEL-1 instrument and the NASA-TEPC. Both instruments follow the same trend, though the DOSTEL-1 data is on average around $8 \%$ lower. This can be explained by (a) the different measurement location of the two instruments which influences the SAA contribution to the total dose and (b) the contribution of neutrons which can only be detected indirectly via elastic scattering or compound nuclear reactions in the DOSTEL silicon detector but are included with higher detection efficiency in the total absorbed dose of the NASA-TEPC

In addition (as partly discussed in Table 13 of Berger et al. 2016) and further expanded now for the whole DOSIS and DOSIS 3D missions, a PDP was always attached at the left side of the DOSIS-MAIN-BOX (see Fig. 1b). Table 6 provides a comparison of the absorbed dose rate measured with the DOSTEL-1 and the DOSTEL-2 instruments with the ${ }^{7} \mathrm{LiF}: \mathrm{Mg}$, Ti thermoluminescence detector data provided by the PDP located at around $15 \mathrm{~cm}$ distance from the DOSTEL-1 and at around $30 \mathrm{~cm}$ distance from the DOSTEL-2 instrument. Data from the DOSTEL instruments was averaged over the relevant mission duration of the measurements of the PDP. As can be seen the data agrees very well within the respective error bars and shows especially the slow decrease in absorbed dose at the end of 2015 due to the ISS altitude change and the increase of the dose in DOSIS 3D Phase 8 in 2016 due to the decrease in solar activity.

This short comparison shows that the data provided by the DOSTEL instruments fits well into the overall radiation environment measured within Columbus for the relevant exposure times. Further on, the data set enables now evaluation and further comparison of data with other active radiation monitors which measured onboard the ISS. This will be done in the further data evaluation process.

\section{Summary and conclusion}

Within the frame of the DOSIS (2009-2011) and the DOSIS 3D (2012-onwards) experiments a detector suite consisting of two active (powered) silicon detector telescopes (DOSTEL-1 and DOSTEL-2) and passive radiation detector packages (PDP) has been applied onboard the Columbus Laboratory of the ISS for the determination of the temporal and spatial variation of the radiation environment. The DOSIS $3 \mathrm{D}$ experiment is continuously measuring the radiation environment in Columbus and will in the future complement the data presented in this work.

The data provided by the active DOSTEL instruments over a timeline from 2009 to 2016 showed the variation of the radiation load inside the ISS which was subject to changes due to (a) solar cycle dependent variations, (b) changes in the ISS altitude and (c) changes in the ISS altitude during the docking of the Space Shuttle to the ISS. The measurements started in the deepest solar minimum of the space era in
2009 followed by a very long and weak solar maximum in the years 2013-2014 and are currently performed during decreasing solar activity leading to the next solar minimum. The ISS altitude changed from $335 \mathrm{~km}$ to over $420 \mathrm{~km}$ over the time of the experiments thereby also strongly influencing the dose due to the crossings of the SAA. The influence of the docking of the Space Shuttle on the radiation load could be observed and quantified for a total number of eight Shuttle dockings to the ISS in the time between 2009 and 2011 and it could be confirmed that the ISS altitude change during the Shuttle dockings is responsible for the changes in the SAA dose.

The absorbed doses measured at the end of May 2016 reached up to $286 \mu \mathrm{Gy} /$ day with dose equivalent values of $647 \mu \mathrm{Sv} /$ day. The full set of data provided over this long time period will further act as baseline for comparison with other active radiation detectors measuring onboard the ISS and as repository for benchmarking of Monte Carlo calculations for the radiation environment onboard the ISS.

Acknowledgements. The CAU, University of Kiel was supported by DLR under Grants 50WB0826, 50WB1026, 50WB1232 and 50WB1533. The participation of the Technische Universität Wien, Atominstitut (ATI), Vienna, Austria in the DOSIS experiments was supported by the Austrian Space Applications Programme (ASAP) under Contract No. 819643. The Polish contribution for the Institute of Nuclear Physics (IFJ), Krakow, Poland was supported by the National Science Center (Project No. DEC-2012/06/ M/ST9/00423). MTA EK greatly acknowledges ESA PECS for the Financial Grant No. PECS4000108464. The participation of the Nuclear Physics Institute of the Czech Academy of Sciences has been supported by the grant of Czech Science Foundation (GACR) No. 15-16622Y.

The authors would like to thank the Sodankyla Geophysical Observatory and the website teams (http://cosmicrays.oulu.fi) for providing the Oulu neutron monitor data. The authors would like to thank Ryan R. Ryos (NASA-SRAG) for providing help to extract ISS orbital data. The authors would like to thank the HIMAC team at NIRS in Japan for providing lots of experiment time.

The authors gratefully acknowledge the support of the European Space Agency (ESA) especially Jason Hatton, Rene Demets, Chiara Lombardi and Liesbeth De Smet as well as colleagues from CADMOS (Lourdes Oro Marot, Cécile Thevenot) Toulouse, France, DLR-MUSC (Pascaline Kerbeci), Cologne, Germany and ESA-EAC, Cologne, Germany.

All of these experiments would have not been possible without the help of all the astronauts working on the DOSIS and DOSIS 3D experiments: Frank de Winne, Tracy Caldwell-Dyson, Shannon Walker, Ron Garan, Mike Fossum, Andre Kuipers, Joe Acaba, Sunita Williams, Chris Hadfield, Chris Cassidy, Luca Parmitano, Michael Hopkins, Rick Mastracchio, Koichi Wakata, Alexander Gerst, Samantha Cristoforetti, Scott Kelly, Timothy Peake, Jeffrey Williams and Takuya Onishi.

The editor thanks Maxim Dolgonosov and an anonymous referee for their assistance in evaluating this paper.

\section{References}

Badhwar, G.D., W. Atwell, G. Reitz, R. Beaujean, and W. Heinrich. Radiation measurements on the Mir Orbital Station. Radiat. Meas., 35 (5), 393-422, 2002,

DOI: $10.1016 / \mathrm{S} 1350-4487(02) 00072-0$

Beaujean, R., J. Kopp, and G. Reitz. Active dosimetry on recent space flights. Radiat. Prot. Dosim., 85 (1-4), 223-226, 1999a.

Beaujean, R., G. Reitz, and J. Kopp. Recent European measurements inside Biorack. Mutat. Res., 430 (2), 183-189, 1999b, DOI: 10.1016/S0027-5107(99)00129-3. 
T. Berger et al.: DOSIS \& DOSIS 3D: DOSTEL radiation measurements on board the ISS

Beaujean, R., J. Kopp, and G. Reitz. Radiation exposure in civil aircraft. Radiat. Prot. Dosim., 85 (1-4), 287-290, 1999c.

Beaujean, R., J. Kopp, S. Burmeister, F. Petersen, and G. Reitz. Dosimetry inside MIR station using a silicon detector telescope (DOSTEL). Radiat. Meas., 35 (5), 433-438, 2002, DOI: 10.1016/S1350-4487(02)00074-4.

Beaujean, R., S. Burmeister, F. Petersen, and G. Reitz. Radiation exposure measurement onboard civil aircraft. Radiat. Prot. Dosim., 116 (1-4), 312-315, 2005, DOI: 10.1093/rpd/nci095.

Berger, T. Radiation dosimetry onboard the International Space Station ISS. Z. Med. Phys., 18 (4), 265-275, 2008, DOI: 10.1016/j.zemedi.2008.06.014.

Berger, T., B. Przybyla, D. Matthiä, G. Reitz, S. Burmeister, et al. DOSIS \& DOSIS 3D: long-term dose monitoring onboard the Columbus Laboratory of the International Space Station (ISS). J. Space Weather Space Clim., 6, A39, 2016, DOI: $10.1051 / \mathrm{swsc} / 2016034$.

Caffrey, J.A., and D.M. Hamby. A review of instruments and methods for dosimetry in space. Adv. Space Res., 47 (4), 563-574, 2011, DOI: 10.1016/j.asr.2010.10.005.

Dachev, T.P., J. Semkova, B. Tomov, Y. Matviichuk, P. Dimitrov, et al. Space shuttle drops down the SAA doses on ISS. Adv. Space Res., 47 (11), 2030-2038, 2011,

DOI: 10.1016/j.asr.2011.01.034.

Dachev, T., G. Horneck, D.-P. Häder, M. Lebert, P. Richter, M. Schuster, et al. Time profile of cosmic radiation exposure during the EXPOSE-E mission: the R3D instrument. $J$ Astrobiol, 12 (5), 403-411, 2012, DOI: 10.1089/ast.2011.0759.

Drobyshev, S.G., and V.V. Benghin. Estimation of the effect of orientation of International Space Station on the dose rate in station's service module when passing through the South Atlantic Anomaly region. Cosmic Res., 49 (5), 399-406, 2011, DOI: $10.1134 / \mathrm{S} 0010952511050054$.

Durante, M., and F.A. Cucinotta. Physical basis of radiation protection in space travel. Rev. Mod. Phys., 83, 1245-1281, 2011, DOI: 10.1103/RevModPhys.83.1245.

English, R.A., R.E. Benson, J. Vernon Baily, and C.M. Barnes. Apollo experience report - protection against radiation, NASA TN D-7080, National Aeronautics and Space Administration, Washington, DC, 1973.

Grahn D., Editor. HZE particles effects in manned spaceflight, National Academy of Sciences, Washington D.C., 1973.

Hassler, D.M., C. Zeitlin, R.F. Wimmer-Schweingruber, B. Ehresmann, S. Rafkin, et al. Mars' surface radiation environment measured with the Mars Science Laboratory's Curiosity rover. Science, 343 (6169), 1-6, 2014, DOI: $10.1126 /$ Science. 1244797.

ICRP. 1990 Recommendations of the international commission on radiological protection. ICRP Publication 60. Ann. ICRP, 21 (1-3), 1-201, 1991.

ICRP. Assessment of radiation exposure of astronauts in space. ICRP Publication 123. Ann. ICRP, 42 (4), 1-339, 2013.

ICRU. Stopping powers for electrons and protons, Report 37, International Commission on Radiation Units and Measurement, ICRU, Bethesda, MD, 1984.

Kroupa, M., A. Bahadoric, T. Campbell-Ricketts, A. Empl, S. Minh Hoang, et al. A semiconductor radiation imaging pixel detector for space radiation dosimetry. Life Sci. Space Res., 6, 69-78, 2015, DOI: 10.1016/j.1ssr.2015.06.006.

Labrenz, J., S. Burmeister, T. Berger, B. Heber, and G. Reitz. Matroshka DOSTEL measurements onboard the International Space Station (ISS). J. Space Weather Space Clim, 5, A38, 2015, DOI: $10.1051 / \mathrm{swsc} / 2015039$

Labrenz, J. Radiation field in low Earth orbit: measurements from MATROSHKA DOSTEL onboard ISS, PhD thesis, Christian
Albrechts Universität, Kiel, 2014, http://macau.uni-kiel.de/ receive/dissertation_diss_00014952.

Lishnevskii, A.E., M.I. Panasyuk, V.V. Benghin, V.M. Petrov, A.N. Volkov, and O.Y Nechayev. Variations of radiation environment onboard the ISS in the year 2008. Cosmic Res., 48 (3), 206-210, 2010, DOI: 10.1134/S0010952510030020.

Lishnevskii, A., M.I. Panasyuk, V.V. Benghin, V.M. Petrov, A.N. Volkov, and O.Y. Nechaev. Variations of radiation environment on the International Space Station in 2005-2009. Cosmic Res., 50 (4), 319-323, 2012a, DOI: $10.1134 / \mathrm{S} 0010952512040028$.

Lishnevskii, A.E., M.I. Panasyuk, O.Y. Nechaev, V.V. Benghin, V.M. Petrov, et al. Results of monitoring variations of absorbed dose rate onboard the International Space Station during the period 2005-2011. Cosmic Res., 50 (5), 391-396, 2012b, DOI: $10.1134 / \mathrm{S} 0010952512050036$

Narici, L., T. Berger, D. Matthiä, and G. Reitz. Radiation measurements performed with active detectors relevant for human space exploration. Front. Oncol., 5, 273, 2015, DOI: 10.3389 /fonc. 2015.00273 .

Reitz, G. Characteristic of the radiation field in low earth orbit and in deep space. Z. Med. Phys., 18 (4), 233-243, 2008, DOI: $10.1016 / \mathrm{j}$. zemedi.2008.06.015.

Reitz, G., R. Beaujean, C. Heilmann, J. Kopp, M. Leicher, and K. Strauch. Results of dosimetric measurements in space missions. Adv. Space Res., 22 (4), 495-500, 1998, DOI: 10.1016/S0027-5107(99)00129-3.

Reitz, G., K. Strauch, R. Beaujean, J. Kopp, M. Luszik-Bhadra, and W. Heinrich. Dosimetric mapping inside BIORACK on shuttle missions STS76, STS81 and STS1984. In: E., Brinckmann, C. Varajão, and M. Perry, Editors. SP1222 Biorack on Spacehab, European Space Agency, Noordwijk, The Netherlands, 161-169, 1999.

Reitz, G., R. Beaujean, E. Benton, S. Burmeister, T. Dachev, S. Deme, M. Luszik-Bhadra, and P. Olko. Space radiation measurements on-board ISS - the DOSMAP experiment. Radiat. Prot. Dosim, 116 (1-4), 374-379, 2005,

DOI: $10.1093 / \mathrm{rpd} / \mathrm{nci} 262$.

Richmond, R.G. Radiation dosimetry for the Gemini program, NASA TN D-6695, National Aeronautics and Space Administration, Washington, DC, 1972.

Singleterry Jr., F.F. Badavi, R.C., J.L. Shinn, F.A. Cucinotta, G.D. Badhwar, et al. Estimation of neutron and other radiation exposure components in low earth orbit. Radiat. Meas, 33 (3), 355-360, 2001, DOI: 10.1016/S1350-4487(01)00049-X.

Uchihori, Y., and E.R. Benton, Editors. Results from the first two inter comparison of dosimetric instruments for cosmic radiation with heavy ions beams at NIRS (ICCHIBAN-1\&2) experiments, HIMAC Report 078, National Institute of Radiological Sciences, Chiba, Japan, 2004.

Uchihori, Y., and E.R. Benton, Editors. Results from the ICCHIBAN-3 and ICCHIBAN-4 experiments to intercompare the response of space radiation dosimeters, HIMAC Report 128, National Institute of Radiological Sciences, Chiba, Japan, 2008.

Warren, C.S., and W.L. Gill. Radiation dosimetry aboard the spacecraft of the eight Mercury-Atlas mission (MA-8), NASA TN D-1862, U.S. Govt. Printing Office, Washington, DC, 1964.

Zeitlin, C., D.M. Hassler, F.A. Cucinotta, B. Ehresmann, R.F. Wimmer-Schweingruber, et al. Measurements of energetic particle radiation in transit to Mars on the Mars Science Laboratory. Science, 340, 1080-1084, 2013, DOI: $10.1126 /$ science. 1235989 .

Cite this article as: Berger T, Burmeister S, Matthiä D, Przybyla B, Reitz G, et al.. DOSIS \& DOSIS 3D: radiation measurements with the DOSTEL instruments onboard the Columbus Laboratory of the ISS in the years 2009-2016. J. Space Weather Space Clim., 7, A8, 2017, DOI: $10.1051 / \mathrm{swsc} / 2017005$. 